\title{
MEDIO AMBIENTE: ANALISIS COMPARATIVO DE LA NORMATIVA COMUNITARIA Y ESPAÑOLA, CON ESPECIAL REFERENCIA A LA ACTUACION DE LAS CORPORACIONES LOCALES
}

\author{
POR \\ Valentín R. Vázouez de Prada
}

\begin{abstract}
SUMARIO: Preámbulo.-España: legislación interna y legislación comunitaria en Medio Ambiente. -La Agencia Europea del Medio Ambiente y el nuevo organigrama competencial español en materia de medio ambiente.-Las estrategias tecnológicas de los 90 y el compromiso comunitario en materia de medio ambiente.-Breve referencia a las Corporaciones Locales en la lucha medioambiental.
\end{abstract}

\section{PREAMBULO}

La creación de.una nueva Agencia Europea como es la denominada de Medio Ambiente ha puesto sobre el tapete muchos interrogantes, aunque lo fundamental con tal decisión, es el compromiso adoptado por las autoridades comunitarias en orden a reforzar sus actuaciones en el campo que nos concierne. Casi inmediatamente, surgió la iniciativa española en orden a solicitar las supremas instancias comunitarias, la instalación de esta nueva Agencia en suelo español, lo que nos obliga a repasar en rápido balance las medidas más recientes que en nuestro país se han tomado sobre la protección medio ambiental, a todos sus niveles territoriales - por supuesto, que con mayor énfasis, a escala nacional, pero sin olvidar a nuestras Comunidades Autónomas y con particular relieve, por la trascendencia que tiene su papel, a nuestras Corporaciones locales-, para de este modo poder colegir cuáles son los méritos que podemos aportar a nuestro "curriculum» respecto al reto que supone la posible ubicación española de la Agencia Europea (1).

(1) En un trabajo anterior aludiamos a cómo las autoridades comunitarias estaban siguiendo en este caso concreto modelos foráneos, y en particular el representado por la célebre agencia norteamericana de Protección Ambiental, cuyas siglas originales son por casi todos conocidas (es la famosa EPA, equivalente a "Environnmental's Protection Agency»), y esto con el objetivo de conseguir una mayor eficacia en la política monetaria sobre el Medio Ambiente. Creada sobre el papel a fines de 1989. España presentaba su candidatura sobre su domiciliación en nuestro país al poco tiempo, sin que desde entonces la Comunidad haya tomado una decisión sobre este punto se ha ido aplazando en la sucesivas reuniones en la cumbre: primero, con la presidencia francesa, durante el segundo semestre de 1989, y después, bajo la dirección irlandesa, en el primer semestre de 1990, sin que en principio la solución aparezca próxima, a pesar, como es lógico, difícil resulta imaginar pueda comenzar a actuar sin tener antes elegido el lugar de su residencia, contrastando en este caso cómo la Comunidad haya conseguido 
Por nuestra parte, se trata de un esfuerzo más que añadir a las varias tentativas realizadas, respecto a subrayar "las presencias» pero asimismo "las carencias» que nuestro país tiene sobre una política ambientalista de alto standard -si no quiere decir, de standar europeo-, que curiosamente ha recibido en tiempos recientes alguna fuerte crítica internacional (hecha en un foro de estas características como ha ocurrido en la conferencia de Bergen, en Noruega, celebrada durante el mes de mayo de 1990, en donde tres países, como fueron Estados Unidos de Norteamérica, Gran Bretaña y España, merecieron los honores de ser los más criticados en este terreno, al no haber permitido la generalización de la prohibición de los famosos productos CFC que a nivel mundial se vienen denunciando como unos de los mayores causantes de las lesiones atmosféricas y en especial, de la llamada ureducción de la capa de ozono" que envuelve nuestra atmósfera, tema que tanta importancia ha adquirido desde que, en la pasada Conferencia Internacional de Londres, se desvelaran sus perjudiciales efectos

En la citada reunión mundial de Bergen, a España le cupo el honor, triste honor, de ser incluida, junto a Gran Bretaña y Estados Unidos, de ser uno de los países más resistentes tanto a la disminución de los ya detectados agentes o factores más agresivos medioambientales como a la admisión, en su consecuencia, de la igualitarización de las condiciones a nivel espacio nacional de carácter protector, lo que a su vez, no es más que reflejo de la resistencia, o si se quiere, silencio "administrativo» que España tiene para recoger en su ámbito normativo los resultados $y$ conclusiones de las múltiples conferencias y debates internacionales que la precedieron y que van incorporándose al acervo comuni-

acuerdos en puntos más conflictivos, cómo el de la misma residencia de sus más altos $y$ políticos órganos, como es el Parlamento, y, en cambio, no lo haya logrado en lo que nos ocupa; logra consolidar sus dos capitales. Bruselas y Estrasburgo, lo que se consigue, incluso, por un procedimiento tan expedito y no muy usual en los ámbitos comunitarios como es la votación a mano alzada, en el primer trimestre de 1990, votación que a su vez obligará a establecer prácticamente dos «sedes comunitarias», lo que inmediatamente ha conllevado la ampliación de las instalaciones francesas de Estrasburgo, ya que al menos en su hemiciclo se desarrollará al menos por mes una reunión del Parlamento Europeo. Parece obvio que si la Comunidad consigue un acuerdo en este campo no sea capaz de conseguirlo en un ámbito menos importante, como es el que analizamos, lo que, a nuestro jucio, puede deberse a soterradas resistencias sobre los méritos que reúnen las potenciales sedes "candidatas», al saberse por todos los páises comunitarios el corto compromiso que tiene nuestro país en el plano de la legislación comunitaria europea de medio ambiente, punto éste al que también nos hemos referido en otro trabajo pendiente de publicación en la Revista de Administración Pública. 
tario mundial a manera de avances que reclaman su ratificación a nivel nacional (2).

A nivel comunitario, los órganos competenciales para poner en funcionamiento la Agencia Europea del Medio Ambiente, vienen retrasando la adopción de la decisión sobre su sede permanente, curiosamente en medio de su continuidad resolutoria de otras medidas de protección ambiental ( $y$ así, mientras que las autoridades responsables representativas de sus dos Estados miembros, de las que muchas tienen categoría de Ministros de Medio Ambiente, siendo en esto también una excepción nuestro país, tan apegado como veremos a mantener a niveles subordinados a los órganos competenciales propios en la materia, aprobaban dos directivas tan importantes que regirán en adelante la experimentación y la comercialización de los organismos genéticamente modificados, regulando así su futuro uso tanto en laboratorios como en medios abiertos) (3), no pasaba lo mismo con un tema que en principio aparecía mucho más anodino como era el de la fijación de la sede de la nueva Agencia. Alguien podrá argüir que toda esta cuestión corresponde tanto a los entresijos burocráticos como a los misterios de una diplomacia comunitaria que en ocasiones -una podría ser ésta- aplaza, suspende temporalmente o alarga con

(2) Causa sorpresa la escasa información que los medios de comunicación social españoles ofrecieron a sus lectores en torno a la Conferencia de Bergen, que contrasta con la que una vez finalizada ofrecieron los canales públicos de televisión, a través de una semana, toda una semana, dedicada bajo el eslogan "Un solo mundo», a destacar las coincidencias comunes. así como las políticas que demandan para todos los países la conservación de un mundo único. que es el que está a nuestro alcance; todavia, por ahora, los mundos extraterrestres no dejan de rayar en la utopía, mientras los avances científicos no prueban la posible habitabilidad de toda esa pléyade de planetas sobre los que tanto se habla, pero que continúan, mal que nos pese, inhóspitos a toda "vida humana». La televisión pública española, a través de su canal 2. participó en dicha emisión común con más de 27 televisiones nacionales, que a lo largo, diariamente, de una semana fueron entrevistando a Jefes de Estado, de Gobierno y de partidos políticos para subrayar la urgencia de una coordinación de políticas para "salvar y proteger a nuestro planeta», ese solo mundo, al que aludia el eslogan. Como introducción a la emisión española intervino el Ministro de Relaciones con las Cortes, señor Zapatero, que aludió al «mayor compromiso" de nuestro Gobierno con las políticas de protección de medio ambiente y exponiendo su punto de vista sobre "el contrato natural» que habría de suscribirse entre los hombres con la naturaleza, algo que, según él, ya se había apuntado por nuestro gran pensador Giner de los Rios, que habló en su época de la Naturaleza como titular de Derechos. Una más de sus grandes ideas, que, como tantas otras suyas, siguen inéditas para muchos españoles.

(3) Es curioso que estas dos Directivas comunitarias se adopten al mismo tiempo que se adopta - a prueba- el Reglamento de la Nueva Agencia Europea de Medio Ambiente, aunque no de su "sede", Reglamento que prevé el aumento de las competencias de la Agencia.pasados sus primeros dos años, lo que en definitiva es la mejor credencial de la propia Comunidad sobre una Agencia que por ahora está sólo sobre el papel, demostrando así los rumbos próximos que tendrá la política de la Comunidad en este campo, similar en tantos otros a los que siguió en su dia el Gobierno federal norteamericano, aunque creemos sabrá sacar partido de esta experiencia ajena para no incidir en sus mismos errores. Véase Letre de Matignon, abril de 1990. También, diario El País de 23 de marzo de 1990. 
demasía, la adopción de cuestiones o decisiones en las que pueden estar interesadas, a su favor, varios de los Estados miembros, con el propósito, no confesado pero real, de conseguir cierto consenso fuera de las reuniones oficiales -a manera de una transacción extraprocesal que justamente nuestra ley de arbitraje privado reconoce con gran aplauso- para de esta manera lograr que la votación dentro de las "paredes comunitarias» sea más relajada y menos dialéctica (4).

Hay que señalar que mientras la Comunidad, como decimos, continúa tomando medidas protectoras del ambiente europeo -ahora, si cabe, más necesarias tras el derrumbe del muro de Berlín que al abrir las puertas de la Europa del Este ha puesto ante los ojos de todos los ciudadanos de la vieja Europa la inmensa destrucción ambiental que han estado sufriendo durante décadas como consecuencias de la planificación socialista casi todos los países sometidos hasta la fecha a la férula comunista (5) - como aquellas a las que acabamos de referirnos, que se adoptan el 22 de marzo, siendo la directiva de las dos citadas más importante la concerniente a la "diseminación»-comercialización- de los organismos genéticamente modificados, previéndose un estudio evaluatorio de los riesgos que conlleva, caso por caso, a cargo de una comisión de expertos nacionales del país en que se lleva a cabo dicha comercialización, que comunicará sus conclusiones a los demás países comunitarios. Ambas directivas, por debajo de su aséptica denominación, se refieren a los llamados «hijos artificiales de la genética», que como todo el mundo sabe, están adquiriendo tan brutal auge que exigía una intervención preventiva y cautelar, como esta de la Comunidad Europea, como paso ad liminen para evitar posibles mayores males irreparables.

No obstante, insistimos, en medio de esta creciente concienciación comunitaria que torna imparables cualesquiera de las medidas previstas o que se proyecten adoptar, dentro de ese cuadro que parece inacabable en razón tanto de su urgencia temporal como de

(4) Normalmente, las negociaciones comunitarias no se desarrollan exclusivamente en un sitio determinado, sino también mediante el recurso a los «teléfonos» y demás campos abiertos a la negociación orbital -despachos, consultas, etc.-, que suponen cesiones mutuas, contraprestaciones, ventajas adicionales..., que permiten llegar en determinados puntos a consensos sobre la mesa formal de las conferencias públicas y solemnes. Las llamadas «conversaciones de pasilios" se muestran con frecuencia más eficaces que las "otras".

(5) La revista Scala, del Gobierno federal germano, dedica un terrible artículo a la destrucción medioambiental en su República hermana, la mal llamada República Democrática Alemana, cuyos ríos y bosques están casi totalmente destruidos por la polución industrial, al igual que en Polonia, en que una gran parte de su litoral báltico está en desuso, incluidas sus históricas y hermosas playas, donde veraneaban los más egregios representantes de las monarquias y nobleza europeas, y que algunos autores famosos, Mann y Mahler, entre otros, recogieron en sus cartas y escritos. En estos paises parece que se impuso este eslogan: el desarrolo industrial exige que la naturaleza debe ser destruida, un delenda est natura, que tanto nos puede sonar a los españoles, tan abandonados como ellos... 
su misma perentoria necesidad, la Comunidad careció de «prisas» para tomar decisión alguna sobre la sede de su oficina medioambiental, cuando lógicamente el retraso en ésta, produce, paralela y simutáneamente, la parálisis en la puesta en marcha de todas sus competencias, considerando, a pesar de todo, que la elección de esa "sede» responde a una opción política que deberá tomarse por los mismos Ministros de Asuntos Exteriores de los doce.

\section{ESPAÑA: LEGISLACION INTERNA Y LEGISLACION COMUNITARIA EN MEDIO AMBIENTE}

Decíamos que España no se ha concienciado, al menos, al nivel reclamado por nuestra pertenencia a la Comunidad, en la materia que nos ocupa y de esto no creemos que sea un fallo exclusivo de las instancias oficiales, a las que resulta cómodo imputar todas las deficiencias y quiebras que pueda experimentar nuestro entorno, sino también es atribuible a todos y cada uno de nosotros $-y$ sobre todo, a nuestras empresas e industrias- que no vemos en el Medic Ambiente algo que tenemos que ver: aquella parte de un espacio cósmico, universal, que nos corresponde y que integra nuestro territorio nacional, del que debemos hacer uso como de cualquier otro bien económico, al estar caracterizado por las notas comunes a los bienes económicos: escasez y poder destinarse a empleos alternativos

Para todos los estudiosos de las ciencias económicas, pero asimismo, para los que tengan nociones rudimentarias en las mismas es de predicamento común que a mayor uso, mayores desperfectos, y que a mayor número potencial de consumidores -usuarios-, mayores utilidades "marginales» podrán obtenerse de los bienes requeridos y demandados. Dado que el espacio disponible lo tenemos ya marcado -siendo inexistentes cualquiera de esas otras opciones históricas que los pueblos tenían al recurrir a las conquistas bélicas para el alargamiento de aquél, como vemos en la historia sobre todo de los países europeos-, si queremos que continúe dando el mismo uso, es preciso conservarlo, y he ahí por qué, por razonamiento tan simple, se impone la comesura y la estimación de nuestro entorno en todas nuestras estimaciones $y$ evaluaciones económico-sociales deberá entrar como una partida de todas las demás que se toman en cuenta desde hace tiempo, y es aquí donde más resalta el comportamiento de nuestros empresarios con los restantes de la Comunidad y de otros países avanzados del mundo, para los que la conservación de lo que ocupan con sus fábricas e industrias, y del espacio que afectan con su actividad industrial, que unas veces será el más próximo que les 
limita, pero que otras, aunque no quieran, será otro mucho más amplio que se extenderá durante muchos más kilómetros a su alrededor -como lo están experimentando algunos bosques de la famosa Selva Negra alemana, con la menos famosa «lluvia ácida» procedente de algunas de sus industrias-, por lo que aceptan tanto en beneficio propio como del ajeno, que corresponde a la sociedad y al Estado, del que forma parte como ciudadano activo, limitaciones y mayores gastos en sus presupuestos, para eliminar o, en su caso, reducir o disminuir, los posibles perjuicios que pueda causar su actividad industrial al medio ambiente que la rodea y que pertenece, por solidaridad y por principios básicos de justicia, a toda la sociedad (6).

A nuestros conciudadanos, sean o no empresarios, nos les ha entrado en mente, semejante visión tan extendida, sino que siguen creyendo que lo que ellos dañan, otros repararán, y que el entorno en el que operan o en el que viven, carece de derechos y ellos pueden dañar o lesionar, sin reclamación alguna. Es una visión medievalista únicamente en el sentido, para nosotros, de estimarse cada uno "un rey en su casa», o como decimos a nivel popular, cualquiera puede hacer de su capa un sayo, puesto que no es correcto en cualquier otro (para muchos de nosotros resultaría sorprendente el respeto que en aquella sociedad medieval existía para los animales y el mismo paisaje, frente a lo que muchos podrían creer, como nos lo revela esa maravillosa anécdota que relata Julien Green en su extraordinario relato biográfico de Francisco de Asís, cuando avisado el santo hermano de la existencia de un gigantesco lobo que destrozaba muchos bienes de los habitantes de una determinada comarca, pidieron su intervención para "exterminarle», lo que el santo de Asís reconvirtió simplemente en el "amansamiento» de tan terrible fiera, que pasó a ser motivo de juego para aquellos que le demandaban su muerte; práctica del santo de Asís que tanto nos habla sobre la necesidad de proteger las vidas de aquellos que, como los animales que nos rodean, forman parte de nuestro espacio vital posiblemente con tantos derechos como nosotros). Aunque en el plano científico e intelec-

(6) ERNST FISCHER, en un breve pero hermosísimo artículo sobre "El caos y la forma", incluido en su libro sobre el análisis de la obra de MUSIL en torno al Hombre sin atributos, Editorial Ayuso, 1970, comienza con estos versos de Aristófanes, en versión de KARL KRAUS: El hombre se ha ido. El aire es puro. Que esto se escribiera hace dos mil años no podrá ayudarnos a pensar en los posibles perjuicios irreparables que causamos por nuestros sistemas de vida, tan centrados en ese dominio bíblico del hombre sobre la Tierra, tan mal e interesadamente interpretado por todos aquellos que la destruyen con su comportamiento egoista, sin futuro, sólo mirando su presente, menospreciando a todas esas generaciones futuras para las que se pide, con toda justicia, mayor precaución y cuidado. ¿Vamos al caos de que habla FISCHER, irrevocablemente? Pero FISCHER se respondía: el rostro del hombre está en su trabajo..., sin frases, sin vaguedad; sobre el caos aparece el rostro del hombre. 
tual, tal concienciación se va dando, la verdad es que falta mucho camino por recorrer contra esa tendencia, como ha indicado el profesor González Bernáldez, en que los empresarios pasen a estimar como parte de sus costes los que corresponden a gastos encaminados a evitar la contaminación del medio ambiente en que va a producirse su respectiva actividad industrial (7), mas esta situación ha contribuido por una parte a que el Gobierno, debido a esta ausencia de conciencia social, haya actuado con cierta reservas en la imposición de medidas coercitivas -dado que los agentes sociales no están por la labor de su adopción voluntaria-, y por otra, a que no se haya tomado un papel igualmente exigente en el respeto de una legislación que, como la comunitaria, hace en ella misma una asunción mayor de unos valores consensuados por toda la colectividad. Lo primero, ha derivado en la adopción de unas medidas débiles, diríamos hoy, «light", enormemente suaves cuyos incumplimientos o no son sancionados, o si lo son, lo son con multas demasiado bajas o hasta ridículas (en términos generales), y por otro lado, lógicamente en una disminución de la fuerza vinculante de la normativa procedente de la Comunidad, lo cual a su vez, está produciendo- a pesar de la discreción aparentemente acordada entre las autoridades comunitarias y nuestras nacionales -con cierta periodicidad, recelos comunitarios respecto al compromiso español sobre el respeto a la legislación comunitaria, que por lo demás, como vemos, no decrece sino, que como es obvio, va en aumento (de donde a las autoridades comunitarias les resulta fácil colegir que si el incumplimiento se está dando ya, más se presentará a medida que vayan aumentando las resoluciones intervencionistas de la propia Comunidad).

Periódicamente tales «incumplimientos» se revisan en un plano bilateral, como así tuvo lugar en la reunión presidida por el Comisario comunitario en asuntos medioambientales, el italiano Ripa di Meana, del 22 de marzo de 1990, en donde comenzó por verse el contencioso en principio volcado sobre el número exacto de infracciones de la legislación comunitaria de las que era acusada en el correspondiente y preceptivo informe interno de los órganos comunitarios, que elevaban las mismas a más de cincuenta, mientras que nuestros representantes las reducían a cerca de

(7) Este autor subraya cómo el empresario o inversionista español ve el medio ambiente como algo que no existe; que está ahí para su exclusivo beneficio y que si lo perjudica o daña es algo que va implicito en su mismo plan. El medio ambiente en esta perspectiva no cuenta para nada (la realidad presente, cada día más, exige un cambio radical en este planteamiento, mediante la inclusión de medidas depuradoras, de ahorro de energía contaminante, de empleo de recursos antipolucionantes, que serán mayores con el paso del tiempol. Cambiar tal mentalidad será obra de todos, pero sobre todo de la imposición oficial de medidas que obliguen a los que tienen que obligar (las declaraciones del Profesor González aparecieron en un semanario de difusión nacional, en marzo de 1990). 
veinte. Ante cifras tan dispares, fácil es también deducir las dificultades inherentes a un proceso donde las partes inician su carrera con datos tan distintos y donde tanto interés hay por la Comunidad para conseguir el respeto de legislación tan necesaria como la que examinamos.

Las diferencias señaladas son, no obstante, tan brutales que por encima de las manifestaciones producidas como naturalmente tenían que producirse (8) revelan a cualquier observador que la parte requerida para una mayor y mejor realización de las directivas comunitarias en materia de medio ambiente deja bastante que desear y son claro testimonio de la necesidad que tiene nuestro país de un más completo y puntual compromiso con todo lo relacionado con nuestro entorno, ya que en definitiva, lo que estipulan todas esas directivas es que contando con un más alto standar valorativo se observen en el propio territorio nacional (9).

Otro significado pueden tener estas "diferencias» sobre el grado de cumplimiento por nuestro país de la legislación comunitaria en materia de protección medioambiental, como es el de que habiéndose incorporado nuestro país con cierto retraso a la Comunidad, lo hizo en un momento en que ésta contaba ya con un extenso bagaje jurídico en esta materia, por lo que si, a la falta de concienciación que hemos denunciado, se viene a sumar este doble factor, se puede sacar la conclusión acerca de la temporalidad que nuestro país debe disponer para ponerse al día, como lo vienen haciendo en otros campos, en éste tan importante para todos, como es el de conservación de nuestro entorno. De nada vale que se pongan dificultades y críticas a tal proceso de adaptación, ya

(8) No hubo imputaciones indiscriminadas lanzadas recíprocamente por cada una de las partes enfrentadas -metafóricamente hablando-, Comunidad Europea y España, sino justificadas por la Comiunidad, aunque reconociendo su Comisario. Ripa di Meana, que algunas de las Directivas incumplidas puede deberse al retraso en el traslado de su contenido, lo que es tanto como reconocer parte de culpa debido al retraso en los procedimientos notificadores de la propia Comunidad a los diferentes Estados miembros, retrasos que no deberian extrañar y que pueden causar cierta sorpresa a cualquier observador exterior, pues los Estados miembros, a quienes se notifica, no permanecen ni han permanecido mientras tanto ajenos a los mismos procesos burocráticos internos comunitarios (véase en esto, por tal motivo, una especie de "protesta» en los límites del fair play, tan importante en los procedimientos de la Comunidad, del signo que sean). A pesar de las anteriores "explicaciones oficiales comunitarias", al parecer la contestación de la delegación oficial española fue la de insistir en las cifras que desde un principio aportaron -o sea, que sólo habían sido 16, y no 57-, como expresó la Comunidad (vid. detalles de esta petite polémica, entre otros medios, en el El País de 23 de marzo de 1990).

(9) Al haber contado los países comunitarios, aquellos que formaban ya la Comunidad cuando España se integró, con un mayor grado de desarrollo industrial, es natural que las normas existentes en ella sobre medio ambiente gozarán de mayor rigor y más altos niveles científicos y jurídicos en su redacción y aprobación, mucho más cuando nuestro pais, integrado o no. debería fijarse en ellos, al corresponder a su contorno cultural más inmediato. En pocos otros campos juridicos el proceso de adecuación de nuestra legislación interna será más beneficioso que en el que nos ocupa. Parece que no valoremos en la justa medida la oportunidad histórica que nuestra adhesión simboliza. 
que de actuar así no se haría más que aumentar el fondo de separación entre nuestras respectivas legislaciones y reducir nuestras "oportunidades» con vistas al "reto»-challanger-que tiene nuestro régimen de iniciativas jurídicas con los ojos puestos en su cada día mayor adecuación al vigente en el resto de los países comunitarios. Las mismas autoridades comunitarias en este terreno no han dejado nunca de reconocer los esfuerzos continuos y constantes que hacen nuestras autoridades en pro del referido acercamiento de ambas legislaciones (en la reunión citada la delegación española aludió a las cerca de cien directivas introducidas en nuestro Derecho positivo, lo que sirvió para que Ripa di Meana afirmara como "enorme» «... el esfuerzo español en materia de protección de medio ambiente...».

Frente a estos juicios "valorativos» procedentes de la Comunidad sobre nuestro grado de cumplimiento de la legislación, cabe ahora, y ya es tiempo, que formulemos nuestras propias consideraciones desde nuestra perspectiva interna $y$, si hemos de ser claros, desde el primer momento, evitando rodeos de signo equívoco, que no contribuyen mas que a la ambigüedad y a la creencia inexacta de nuestro mayor compromiso ambientalista, observaremos, para tener algunas pistas indiciarias, tanto en las páginas de nuestro Diario Oficial como en la legislación recientemente publicada sobre el particular.

En relación con los contenidos, a la postre la parte más decisiva e influyente de todas las posibles modificaciones adoptadas (10), habría que decir que, a pesar de regir en nuestro país el sistema de evaluación del impacto ambiental, que se comunican a la opinión pública, a través de las páginas del referido Diario, mediante Resoluciones de la Dirección General del Medio Ambiente, en virtud de las competencias atribuidas por el artículo 22 del Reglamento para la ejecución del Real Decreto Legislativo 1302/1986, de 28 de junio, que introduce en nuestro sistema la citada evaluación, no son numerosas las declaraciones -léanse "resoluciones»- de estas características, lo que a sensu contrario nos puede demostrar que en la mayoría de los casos no se presentan las oportunas y

(10) Esto lo decimos por encima y más allá de todas esas modificaciones "orgánicas» que por algunos se utilizan para sobreponer nuestra posible actividad en el campo ambiental, como si con crear una Secretaria de Estado -y no un Ministerio- fuera suficiente para emblematizar nuestro mayor compromiso proteccionista y ecológico-no ecologista, tan identificado esto con signos políticos de alcance radical, más que en un catálogo serio de búsqueda de normas $y$ soluciones. En el sector de organización, nuestro pais parece responder más a motivaciones puramente coyunturales que a una visión a largo plazo de los objetivos que quiere $y$ desea conseguir a medio y largo plazo. La última, por ahora, de estas actuaciones orgánicas está en la Orden del Ministerio de Obras Públicas de 13 de marzo de 1990 (Boletín Oficial del Estado del 20) sobre delegación de atribuciones de la recién creada Secretaría General de Medio Ambiente. 
preceptivas declaraciones para instar de los servicios administrativos el dictado de este tipo de resoluciones y que tal semejante ausencia de solicitudes particulares continúa dándose por falta de control o de vigilancia administrativa en el cumplimiento de dicho Real Decreto Legislativo (citemos como más reciente la contenida en el Boletín Oficial del Estado de 9 de marzo de 1990).

Sobre el campo industrial apenas se han tomado medidas proteccionistas ante la posible contaminación en lo que llevamos de año, como son la Orden de 29 de marzo de 1990 (Boletín Oficial del Estado del 29) sobre método de referencia para humos normalizados. Mayores han sido las medidas específicas adoptadas para la protección de la fauna y el paisaje, como es la Orden conjunta de los Ministerios de Relaciones con las Cortes, Agricultura y Sanidad y Consumo estableciendo normas relativas a la protección de animales en el transporte internacional (Orden de 9 de marzo de 1990, publicada en el Boletín Oficial del Estado de 5 de abril), por el que se regula el Catálogo Nacional de Especies Amenazadas y que se dicta en desarrollo del artículo 30,1, de la Ley 4/1989, de 27 de marzo, de Conservación de los Espacios Naturales y de la Flora y la Fauna Silvestre (11).

En el campo autonómico se ha producido alguna manifestación interesante que conviene citar como prueba tanto de nuestro Estado de Autonomías como del rol que están llamadas a ocupar nuestras Comunidades Autónomas, tan relevante o más, en principio, que el del proipio Estado, al tener los problemas medioambientales una característica tan particular como es su mayor conexión con las necesidades ciudadanas. Así mencionaremos como más destacadas (la mención de estas disposiciones y medidas, al mismo tiempo, sirven para revelarnos, a pesar de su complementariedad básica, algunas deficiencias de la normativa estatal) la Ley de la Comunidad Aragonesa número 2/1990, de 21 de marzo, de Declaración de Monumentos Naturales de los llamados «glaciares pirenaicos» (reproducida en el Boletín Oficial del Estado de 6 de

(11) Contra toda previsión lógica, y como un signo más de la escasa conciencia popular y nacional sobre nuestra temática, esta Ley protectora de 1989, que apenas acaba de arrancar en su aplicación, está recibiendo fuertes críticas contestatarias por parte de las Federaciones de Cazadores, a nivel provincial y, por supuesto, a nivel nacional, ya que, a su juicio, las limitaciones previstas en esta Ley, que justamente van encaminadas a proteger a las especies animales que están en trance de desaparecer -si es que no lo han hecho ya cuando se pongan en rodaje sus previsiones normativas - van directamente en contra de la caza y todo lo que ésta lleva consigo. Ante semejante postura obstruccionista, como si sólo los intereses de los cazadores, por muchos que sean, sean preferentes por encima de todos los demás intereses -por ende, de los millones de españoles que no son cazadores ni les gusta la caza-, ¿qué pensarían y cómo actuarian estos contestatarios si en nuestro país se hubiesen sugerido, simplemente sugerido, algunas iniciativas de carácter tan radical como las habidas en Italia, donde se ha abogado en los últimos años por la supresión del «derecho de caza», considerado como una manifestación medieval? Mejor es no imaginarlo. 
abril), y en el terreno de los proyectos el presentado últimamente en la Comunidad de Castilla y León -por mediación de los representantes de algunos partidos políticos con representación en su Parlamento- acordando un texto legal de prevención del impacto ambiental, como otro similar para la Comunidad de Madrid, Comunidad en la que la adopción de cualquier medida o proyecto de signo proteccionista es bien recibido, al ser una de las Comunidades con mayores necesidades en el campo de los espacios a proteger, así como de las especies a conservar, y cuya simple enunciación demuestra lo que antes señalábamos sobre la escasez de resultados que viene teniendo la legislación estatal del mismo nombre (por si fuera esto poco, la insuficiencia de la legislación municipal de ámbito exclusivamente madrileño está teniendo su reválida a través de su revisión por los expertos comunitarios, otra manera de colaboración oportuna).

La actividad comunitaria en materia medioambiental es incesante y es una de sus áreas competenciales, en donde su actividad viene a ser más insistente, lo que cualquier interesado en el tema puede comprobar con sólo su aproximación a las múltiples fuentes de conocimiento y divulgación de la misma (12), a lo que coadyuvan incluso los propios medios de comunicación social, que, tan atinados siempre en las cuestiones de actualidad, han visto en esta temática una de las más altas en el reclamo popular.

Esta creciente actividad comunitaria viene además impulsada, por si fueran pocos sus factores generadores dentro de la misma Comunidad Europea, por los contactos, concluidos en forma de acuerdos en muchas ocasiones, con los países del Tercer Mundo o de los países en vías de desarrollo que, al concentrar sus mayores potencialidades comerciales en las actuaciones de carácter primario, normalmente derivadas de la explotación de la tierra y restantes recursos naturales, son aquellos que con más urgencia están patentizando gravísimos problemas en sus niveles tradicionales de vida por el más intensivo uso que en ellos se está haciendo para compensar, por un lado, sus crecientes necesidades alimenticias, y por otro, para equilibrar sus propias balanzas de pagos al disponer únicamente de sus productos primarios para poder conseguir mayores cuotas de comercio internacional. Es en las relaciones con estos terceros países donde la Comunidad Europea está viendo las ingentes e innumerables necesidades que todas estas naciones, esencialmente africanas y asiáticas, junto a las sudamericanas,

(12) El lector de esta Revista de Estudios e Investigación de las Comunidades Europeas dispone dentro de sus páginas de un apartado en el que con detalle podrá encontrar todas las medidas adoptadas por la Comunidad durante el periodo de tiempo a que se refiere la selección, $y$ al que nos remitımos, para completar las indicaciones expresas de medida que supra hemos hecho y con el único propósito, en su reducción, de evitar toda monotonia en su repaso.

REVISTA DE ESTUDIOS.-7 
están exponiendo en todos los foros internacionales, y especialmente en aquellos que, como los propios de la Comunidad Europea, tienen para ellas tan gran alcance, siendo raro el día en que cualquiera de estos países no va a Bruselas para conseguir mayores ventajas en sus relaciones bilaterales o para aquellos grupos reducidos de los que forman parte para obtener determinadas ventajas tarifarias (13). Los analistas extranjeros no dejan de incluir estas consideraciones en sus estudios, aunque las hagan más con un carácter global y a veces casi de pasada e indirectamente que en profundidad y con matices exclusivos (como podemos ver, en esta misma revista, en su número 10 , en el trabajo publicado con la firma de DIETER FRISCH en torno al gran mercado europeo de 1992 y los países en desarrollo).

Y eso que, como tuvimos la oportunidad de denunciar, si es que así pudiera hablarse, en un trabajo (14) la Comunidad está recurriendo en exceso al empleo de las Directivas, por encima y más allá de lo que un uso mesurado de las mismas podría aconsejar, exhibiéndose demasiado conforme con los parámetros de conducta de distintos Estados miembros de la misma, que están operando, pensamos, como lastre de la misma Comunidad en la puesta en marcha de una política medioambiental más dinámica y agresiva, con mayor utilización de la técnica de los Reglamentos, siempre más inmediatos y directos tanto en sus medios como ensus resultados. La Directiva exige más conformismo y más contemporización con posiciones de claro signo recalcitrante, aunque es comprensible en una Comunidad económica y política como es la europea, que tanto se ha caracterizado por algo que ha sido y ha venido siéndolo, uno de sus rasgos: dos pasos hacia delante y uno

(13) Pocos autores, al analizar estas relaciones Comunidad-países subdesarrollados, fijan su mirada en estos aspectos tan importantes para todos, comunitarios o no, como son los relativos a la protección de determinados cultivos en aras de conseguir una mayor protección ambiental. Debiéramos hacerlo todos en virtud de ese «único mundo» que todos integramos y en virtud de atender cada vez más a ciertos condicionantes no puramente económicos en las relaciones económicas internacionales (cuán elogiables son algunas iniciativas tomadas por estos paises pobres que aun en su miseria quieren ser, en su medida, conservacionistas, como la que tomaron aquellas mujeres del norte de la India que, abrazadas cada una a un árbol, se oponian asi a una desforestación que evitaba la destrucción total de su entorno, copiando, a su manera, el viejo ejemplo francés de "apadrinar» un árbol).

(14) Pendiente de publicación en las páginas de la Revista de Administración Pública, en donde ya destacábamos esta aparente contradicción que viene revelando la politica comunitaria en relación con la problemática medioambiental, al remitirse, tanto como hace, a la Directiva que. como todo el mundo sabe, de acuerdo con su definición en los mismos Tratados comunitarios. en cuyo artículo 189 resultan palpables las grandes diferencias operativas que tiene frente al Reglamento: «El Reglamento tendrá un alcance general. Será obligatorio en todos sus elementos y directamente. aplicable en cada Estado miembro. La Directiva obligará al Estado miembro destinatario en cuanto al resultado que deba conseguirse, dejando, sin embargo, a las autoridades nacionales la elección de forma y de los medios." Ver Documentación Administrativa, 206-207, octubre-diciembre 1985, enero-marzo 1986, "Comunidades Europeas». Tratados constitutivos, modificativos, Tribunal de Justicia, Acta Unica, INAP. 
hacia atrás, procedimiento que, si bien en cierto modo le fue impuesto, creemos, que al haber alcanzado las cotas de desarrollo que ya posee, tiene ahora la oportunidad más favorable que nunca para recurrir al Reglamento como método sumamente apropiado para conseguir aquellos fines que en nuestro campo se definen como prioritarios y urgentes. Confiemos que en el balance de la Comunidad en los próximos y decisivos se vaya imponiendo la opción «reglamentaria» por encima de la «directiva».

Con las directivas todos estamos viendo lo que se está consiguiendo: la eficiencia en las mismas previsiones comunitarias -que, como ya hemos dicho, dilata sin explicación alguna plausible la aprobación de una sede para su propia nueva Agencia de Medio Ambiente, lo que a su vez está repercutiendo en su puesta en funcionamiento con la pérdida de trascendencia que se ha dado a esta nueva oficina europea en el terreno mismo de la coordinación y de la profundización informativa de las políticas de medio ambiente de la Comunidad y de sus Estados miembros-, la relantización en el cumplimiento de sus mismas previsiones incluidas en los propios Planes Cuatrienales de Acciones en la materia que nos ocupa, y por supuesto, lo último, pero no lo menos importante, entre otros efectos, el retraso en la creación de una verdadera y auténtica política comunitaria al seguir respetándose en exceso a través de las directivas la visión que tienen sobre aquéllas los mismos Estados miembros, que aplazan sine die la adopción de medidas aconsejadas por un instrumento tan débil, para nosotros, como son las directivas, origen a su vez de múltiples contenciosos que enrarecen todavía más el ambiente.

Casi todos los autores, por neutrales y asépticas que sean sus disciplinas, se ven llamados a lo que ya no sólo para la Europa comunitaria constituye un reto para los tiempos presentes, sino que lo será con fuerzas renovadas para el futuro, y con mayor realce para todos aquellos otros continentes que por su mayor densidad demográfica están llamados, a su vez, a ocupar por este peso natural y poblacional una mayor relevancia en las décadas próximas, principalmente en la materia que examinamos, sobre la que esa enorme densidad demográfica gravitará con extraordinaria gravedad, como ha puesto de manifiesto, cuando preparábamos el presente trabajo, el informe patrocinado por las Naciones Unidas sobre el crecimiento en los próximos decenios (15). Así, por

(15) El informe dirigido por un antiguo Ministro de Desarrollo paquistaní, Ul Haq, contiene previsiones tan llamativas como que la población mundial en el año 2030 será de 11.000 millones de personas y que su 80 por 100 estará aproximadamente en los paises que hoy día están situados en el Sur, identificados con el subdesarrollo y la pobreza. Cuando creiamos muerto a Maltus, renace, sin que los observadores hayan parado mientes en ello, admitiendo fatalmente lo que se les ofrece como conclusión de un estudio. Tan clamorosas tienden a ser 
ejemplo, SANTAMARIA PASTOR no puede por menos que aludir a toda esta pesimista temática global «El sólido equilibrio del llamado con fortuna "navío espacial Tierra" no está amenazado solamente por la industrialización, sino por otros dos factores en cierta forma contradictoria...: de un lado, el brutal crecimiento demográfico, que hace duplicar la población del planeta cada treinta o treinta y cinco años..., y como siniestro contrapunto, la de la muerte...: la humanidad dispone hoy de medios bélicos más que sobrados para aniquilarse a sí misma como especie en pocos días...) (en su extraordinaria obra sobre los Fundamentos del Derecho Administrativo, tomo I, dentro de un capítulo que por algo titula «La era de la incertidumbre» y que no es más que el testimonio, uno más, pero procedente de una de las mentes más lúcidas y rejuvenecedoras de nuestro ya clásico Derecho Administrativo, que ni como Ciencia social ni como rama del Derecho, una de las más vivas y atentas a la realidad de todo el viejo $y$ añoso tronco del Derecho, pueden permanecer al margen de todas las cuestiones que analizamos, y en particular, de las relacionadas con el medio ambiente) (16). Antes, casi inmediatamente, ha escrito esto otro que puede servirnos para cerrar nuestra cita de tan prestigioso estudioso de los más estimulantes empujes de nuestra actual ciencia jurídico-administrativa: «... los dos problemas que la especie humana tiene planteados son obvios: el agotamiento de los recursos naturales del planeta y los daños irreversibles que la civilización industrial está ocasionando al ecosistema global... El progreso industrial ha permitido

\footnotetext{
las diferencias Norte-Sur que, coincidiendo con la publicación del informe, se realizó una campaña en torno al lema «Un solo mundo», que tuvo una versión gráfica en un relato imaginario en el que no se sabía si predominaban en él aspectos de ciencia-ficción o si, por el contrario. respondia con todas sus consecuencias a las citadas "oleadas de población», pues intentaba reproducir una especie de nuevo éxodo, pero no ya limitado. como fue el tradicional éxodo judio, de un único pueblo por otro, inmensamente mayor, en el que pariciparian todos los pueblos infradesarrollados que procedentes del Sur se aproximaban a las costas europeas para obtener del Viejo Continente esa ayuda que les es tan necesaria, y de no obtenerla, "para que los europeos ricos vean cómo morimos». Terrible alegato en un mundo abocado en principio a una mayor radicalización de las diferencias entre sus pueblos.

(16) Véase Juan Alfonso SANTAMARIA PASTOR: Fundamentos de Derecho Administrativo, Editorial Centro de Estudios Ramón Areces, Madrid, 1988, en especial, pp. 178 y ss. También puede consultarse, con una visión más optimista y también más economicista, pero con un enfoque "tercermundista», Luis JIMÉNEZ HERRERO: Medio ambiente y desarrollo alternativo. Gestión racional de los recursos para una sociedad perdurable. Ed. lepala, Madrid, 1989. Destaquemos en sus capítulos, los relativos al «comercio internacional, proteccionismo y deuda: nuevas presiones ambientales para el Tercer Mundo de los ochenta (XIV) y el de upolítica y planificación ambiental en la estrategia del desarrollo" (XVIII). Se trata de uno de los mejores estudios, redactado originalmente en castellano, en una materia de la que tanto se ha abusado en traducciones, y por lo tanto, una brillante aportación a toda esa larga lista de trabajos de investigación extranjeros que desde hace bastante tiempo quisieron llamar la atención de las naciones desarrolladas sobre los graves conflictos que en el plano interno, y particularmente, por esto, en su medio ambiente, están padeciendo los pueblos colocados en la parte sur del mundo, justamente aquella zona geográfica que se identifica con los bajos, los más bajos niveles de renta, y las más pobres y mermadas economias sociales.
} 
acrecer hasta limites insospechados el nivel de bienestar material y cultural de una parte de la población del globo, pero ha envenenado los mares y los ríos, está devorando los bosques, ha hecho palidecer definitivamente el sol sobre muchas ciudades..., ha convertido su entorno en basureros y ha depositado en la atmósfera un nivel de dióxido de carbono que puede provocar cambios radicales en el clima.»

Es verdad que en medio de este mare mágnum de informaciones, en ocasiones, contradictorias, destacan los distintos niveles, así podríamos considerarlos, que aquéllas tienen según su procedencia, puesto que en los países desarrollados, como son fundamentalmente los europeos, su mayor riqueza permite a la misma Comunidad Europea a una mejor y más completa valoración económica que tienen tanto daños en el medio ambiente como los remedios, y su coste, que tiene el ir contra ellos (con la excepción, como ya hemos dicho, por ahora de nuestro país, en donde no existe ni a nivel oficial ni particular esa conciencia del carácter lesivo de algunas de las actuaciones sobre nuestro entorno), con un sentido gradual que supera las limitaciones demostradas de anteriores políticas globales (como ha sucedido con la legislación europea sobre combustibles que sucesivamente ha ido perfeccionando sus mecanismos internos y prohibitivos, hasta la tipificación de un conjunto de gasolinas que finalmente se han demostrado como más idóneas y antipolutivas).

Lo que sí hay que subrayar es que estimamos demasiado lenta esta evolución, así como el gradualismo de sus actuaciones, que están permitiendo, según algunos críticos, que se produzcan daños irreparables a un medio ambiente tan gastado como el de nuestro viejo continente, en el que comenzaron a desarrollarse actividades industriales antes que en cualquier otro lugar del mundo, por lo que, si no cayéramos en la utopía - por lo demás, tan sana para conservar nuestra misma lucidez-, postularíamos un año -que sería más- de carácter sabático que permitiera a nuestro viejo y gastado terruño el descanso que todas las actividades humanas merecen (similar a esa tradicional técnica de nuestros viejos y tradicionales agricultores, con sus tierras en barbecho).

\section{LA AGENCIA EUROPEA DE MEDIO AMBIENTE Y EL NUEVO ORGANIGRAMA COMPETENCIAL ESPAÑOL EN MATERIA DE MEDIO AMBIENTE}

Siguiendo con el paralelismo que intencionalmente hemos venido estableciendo entre estas dos esferas u órdenes de competencia, como son el Ordenamiento comunitario europeo y el 
Derecho Español, conviene que resaltemos, autonomizándoles, los aspectos relacionados con la vertiente orgánica u organizativa que la problemática medioambiental ha producido en cada uno de ellos, que por esos azares del destino, atribuibles a esos espíritus malignos cowardianos, algunos achacarían a la mayor de las casualidades, pero que para nosotros no son más que expresión de la inquietud común en ambos Ordenamientos por una adaptación urgente y perentoria de sus hasta entonces estructuras organizativas, con otras, en principio, más capacitadas para hacer frente a los nuevos retos, surgidos o que pueden hacerlo, que inciden/incidirán en nuestros entornos.

Como ya tuvimos oportunidad de explicar en otro trabajo más amplio sobre este punto, la Agencia Europea del Medio Ambiente nace como el primer intento en la Comunidad Europea de potenciar sus enclaves orgánicos y de centralizar sus dispersas y sucesivas intervenciones medioambientales en un organismo que a través de su misma unitariedad lograse "focalizar" tanto los problemas como las respuestas a los mismos (17). Con referencias en el modelo clásico norteamericano, muy apropiado por lo demás, dada la estructura federal de este último, que, aunque no pueda ser reproducida por la Comunidad Europea (aún no decidida claramente por el mismo, debatiéndose entre este y el otro de corte confederal, que en una primera fase de una Europa más unida políticamente aparece como más adecuado) (18), le ofrece la ventaja de superar cualquier imitación de tipo centralista o centralizado, que presentan la mayoría de los países miembros.

(17) Nuestro trabajo sobre esta nueva Agencia Europea sobre Medio Ambiente se publica, con este título, en el número 13 de la Revista de Estudios e Investigación Europea, del Centro de Estudios Europeos, de la Universidad de Alcalá de Henares, y Edersa, y que creemos ha sido uno de los primeros o más tempraneros dedicados al nuevo organismo europeo que, si bien nace con muchas esperanzas, como cualquier otra nueva vida que advenga a este mundo, 10 hace como fruto de una experiencia propia comunitaria que venía reclamando la instauración de una Oficina o Agencia de tales caracteristicas, que sirviese además para protagonizar más intervenciones en un campo que también en la Comunidad, se confiese $o$ no, ha estado ocupando un rol marginal, dentro o «fuera»-al margen-de las políticas comunitarias básicas en el campo agrícola, industrial, etc., únicas políticas, las sectoriales, en las que cabia, según los Tratados fundacionales, la contemplación de aspectos no totalmente ortodoxos de las mismas. pero convenientes para una mayor atención a las incidencias medioambientales de ella.

(18) En la reciente cumbre de Dublín, en la que, según los expertos, se dio un gran paso -y así lo aseguraron las autoridades asistentes de nuestro país-, se barajó y discutió el proceso a seguir para esa mayor unidad política (gráficamente, una de sus fases protagonistas, que los medios de comunicación se encargaron de difundir urbi et orbi, fue la de la señora Thatcher. cuando manifestó que «no quería perjudicar a su Reina», como dando a entender que la unidad política, si se hace, de momento, tiene que respetar las instituciones básicas del estado de sus países miembros), que se redujo, según declaración final, a dar el visto bueno a una próxima conferencia intergubernamental sobre esta temática, con otras palabras, otra conferencia, pero en exclusividad dedicada a este punto. 
La Agencia Europea de Medio Ambiente es un proyecto que, emergido a finales de 1989 (19), se dirige a ofrecer a terceros y a los mismos Estados miembros esa imagen de unidad y de actuación coordinada que cada día aparecía como más necesaria, cuando los mismos Planes cuatrienales de acción de este campo habían demostrado a todos la justificación de su razón de ser. Los retrasos que se han venido sucediendo, como ya hemos constatado, que en nada le benefician, no restan causas suficientes para el pesimismo, pues su existencia está asegurada, al habérselas dado la correspondiente partida de nacimiento.

Sobre lo que será, como en tantos otros órganos, el futuro nos lo dirá, puesto que, según la famosa ley de Lamarck, se requiere antes el órgano, para que sepamos cuál será su función, y aunque ésta tenga un primer esbozo con su creación, la verdad que será su puesta en funcionamiento y su ulterior desarrollo los que nos dirán cuáles podrán ser sus objetivos y sus competencias. De salida, en ella se centralizan todas las atribuciones dispersas en los restantes Organos comunitarios -principalmente la Comisión que por ser superior continuará con su papel directriz- y tiene en estos orígenes más un vestido de corte estrecho y esencialmente coordinador que novedoso y "a la páge», confiando, como más o menos han confesado las mismas autoridades comunitarias, que el rodaje y su andadura vayan permitiéndola conseguir aquella estatura y pose que convienen a Comunidad tan importante como la europea. Al final, todo dependerá de los compromisos que vaya adoptando como a los «rapports» que vaya elevando a los demás órganos comunitarios, y especialmente a la Comisión (recordemos cómo el papel que actualmente ocupan y desempeñan estos otros órganos comunitarios ha dependido de cómo han sabido jugar sus "chances», como con cierto argot lúcido se dice de los actores en juego o en escena).

(19) El año 1989 ha sido uno de los más relevantes en todos los campos en la Comunidad, y con la presidencia española se alcanzaron unos objetivos que trascenderán al mismo año de su celebración, sobre todo ante la proximidad de 1993, fecha a partir de la cual la Comunidad Europea pasará a ser auténticamente un mercado interno único, con todo lo que esto represente en el plano de politica exterior $y$ demás politicas de la Comunidad. Aunque no todos los engranajes de la gigantesca rueda que es la Comunidad van al mismo nivel, léase altura, lo cierto es que el acelerón experimentado por algunos repercute, como no podía ser menos, en los restantes, que por muy resistentes a los cambios que puedan ser no pueden permanecer ajenos por largo tiempo a los cambios laterales. Se lograron grandes avances en bastantes campos. y uno de ellos, en nuestra modesta opinión, fue dar vía libre a esta Agencia del Medio Ambiente. de la que esperamos que con el paso del tiempo se convierta en la vedette de toda la Comunidad, pues sus actuaciones están destinadas a ser las más deseadas -como, por algunos, también lo serán como las más temidas-, sobre todos aquellos que parodiando a un personaje de la vida pública española "no son inocentes", puesto que el que lo sea nada tiene que temer. Auguramos, no obstante, un primer período conflictivo y de lucha ante resistencia que tendrá que vencer, por algunos de los Estados miembros. 
Aunque algunos críticos hayan lanzado sus campañas al mayor de los pesimismos -lo que tampoco constituye ninguna novedad-, amparándose en el excesivo mimetismo que se ha tenido con relación a otros modelos ya en funcionamiento, conviene que subrayemos que el empuje no está en la originalidad -que sería otra fuente potencial de dudas sobre su posible eficacia-, sino en su acomodación con los objetivos que se la marcan y los fines a perseguir.

En España, las insuficiencias atribuidas a la misma organización y distribución de competencias en materia medioambiental han sido uno de los puntos críticos más reconocidos por todos, hasta el extremo que es raro e infrecuente no ver ni leer en cualquier estudio de nuestra política medioambiental una referencia, por pequeña que sea, de alto sentido crítico contrario a su situación actual, sobre todo, a la existente con anterioridad a la que vamos a mencionar, que aún sin haber parado tales críticas y haberlas dejado en su punto muerto, ha contribuido a reducirlas mientras no se constate su fracaso; es como una carta de crédito que se le otorga, mientras no demuestre su inoperancia, la cual, como se puede comprobar, es harto temprano para dársela -temiendo sin embargo que al final, cual espada de Damocles, caiga sobre la víctima (20).

Con la creación de la llamada Secretaría General de Medio Ambiente se intenta, al igual que hemos visto en la Comunidad, y casi por las mismas fechas, una mayor armonización hacia el exterior de la hasta entonces vigente estructura competencia y orgánica en Medio Ambiente (21) como una mayor profundización

(20) Por todas estas reformas que vamos a citar, pensamos y deducimos un mayor compromiso gubernamental con las tareas protectoras en materia de medio ambiente, como si por primera vez nuestro Gobierno reconociese que se ha alcanzado ese punto limite de no retorno, del que no se puede volver y si en cambio avanzan siempre que se persevere en el camino justo y adecuado. Creemos que también por primera vez en el Ministerio de Obras Públicas y Urbanismo, que no ha dejado de ser el departamento ministerial en la materia que nos ocupa más sustancial y diriamos que "la matriz" de toda ella en el terreno de las competencias administrativas, se percibe una mayor preocupación, ahora exteriorizada con hechos y "medidas», de matiz proteccionista, por lo que podemos confiar en que nuestro Gobierno cada día del presente y del inmediato futuro, vaya demostrando más atención y respecto por todo lo que huela a naturaleza, entorno, medio ambiente, anticontaminación, etc., que redunda en la mejor conservación de todo nuestro ecosistema, uno de los más completos y variados de toda Europa.

(21) Es triste y lamentable la historia burocrática de nuestros órganos competenciales en medio ambiente, sobre todo, tras aquella experiencia, desgraciadamente fallida, que se llamó la "CIMA" -Comisión Interministerial de Medio Ambiente- una de las experiencias que pudo haber salido bien, con lo que ya hubiéramos contado con un órgano uexperimentado" $-y$ no como ahora, un órgano nuevo, cuyo balance final dependerá tanto del titular como de los apoyos políticos, al máximo nivel ministerial, que tenga-. La Comisión Interministerial de Medio Ambiente apareció dentro de aquella «rara avis» que fue en nuestra tradicional organización ministerial, el llamado Ministerio de Planificación del Desarrollo, que creado en la última etapa franquista, respondió más en sus secretas instancias motivadoras, en dar un puesto de Ministro a persona sumamente ligada con el antiguo Jefe de Estado, que a una visión racional y cientifica de las necesidades que pretendia cubrir; dentro de él, y cómo nadie sabia para lo que iba a servir 
de sus competencias, que al centrarse y girar alrededor de un centro directivo de cierto nivel -aunque no el anhelado de una Secretaría de Estado, e incluso, de rango ministerial, sinónimo al existente en otros países, incluidos los europeos- que permitirá mayor fuerza en sus decisiones, así como un mayor respeto en sus intervenciones. Reducidas hasta su creación la vertiente orgánica principal de medio ambiente al nivel de Dirección General, su elevación de rango repercute inmediatamente en la mayor cualificación e importancia de todas sus decisiones, aunque lógico es ya adelantar que su ejercicio dependerá tanto de la dotación de recursos económicos con que se la provea presupuestariamente, como de los medios que como consecuencia de lo anterior, vaya siendo llenada, proceso en el que todavía nos encontramos habiendo ido apareciendo flecos de esta organización a lo largo del presente año.

Para todos los preocupados por la materia que nos entretiene los días anteriores a esta urefundación orgánica» fueron apasionantes al irse entonces desgranando las diferentes opciones que a los políticos se les presentaban en torno al modelo orgánico a adoptar (barajándose como hemos dicho brevemente los tipos de Ministerio, Secretaría de Estado...) que al final se decidió por el de una Secretaría General que es más que una Dirección General -con lo que se sale al paso de los conflictos no siempre públicos de y entre los distintos centros directivos de este rango que tienen competencia más o menos expresas, más o menos directas, sobre Medio Ambiente- y que no alcanza a ser una Secretaría de Estado, con la cercanía que tiene a las más altas cumbres del poder y a su

\footnotetext{
-lo que luego probó su total fracaso y desaparición de nuestra escena politica-, se fueron constituyendo sinnúmeras Comisiones -duplicadas y triplicadas hasta la saciedad, a través de las mismas Comisiones del Plan de Desarrollo- por lo que en medio de semejante cuadro, la aparición de la CIMA, diríamos, que pasó en su primer momento, desapercibida. Con el transcurso de los meses, y como sus miembros no querian ser simples jarrones chinos, sin querer, fueron interviniendo o poniendo «pegas», y lo que pudo ser un embrión espléndido de una organización "competente», se quedó en mera sombra. Está por hacer la historia au detail de nuestra historia burocrática que es tanto como decir, la historia secreta del anterior régimen, del que van comunicándose a la opinión pública, ligeros escarceos -a manera de las consideradas baby-talks, especie de balbuceos infantiles-. Con mayor rango, puede leerse, la reciente autobiografía del profesor López Rodó, titulada precisamente Memorias -tomo l, pendiente el II- (marzo 1990). Aunque discrepemos, puede ver el lacerado e hiriente juicio más subjetivo que critico, de Joan Barril, en El País del 29 de mayo de 1990. El porqué fracasó la. CIMA, como han fracasado otros interesantes proyectos burocráticos, como ha sido el caso de las Confederaciones, similares en tantos aspectos, como destacó algún sector doctrinal, a las famosas "Authority" norteamericanas, como la del Valle de Tennessee. Resulta también extrañísimo., constatar el nulo papel que vienen teniendo los propios funcionarios en la descripción de los órganos en los que viven $y$ que tanto critican, pero como ocurre con frecuencia en nuestra sociedad, sólo de boca, por lo que el humo de sus diatribas se difumina como el de las tracas $y$ nadie mejor que ellos para examinar las contradicciones en las que viven y "funcionan", cuando lo hacen.
} 
participación en determinadas deliberaciones de Consejo de Ministros.

Verdad es que el Ministerio de Obras Públicas y Urbanismo, de quien depende esta nueva figura burocrática, ha venido en los últimos años, y sobre todo durante 1989, a ejercer más vitalmente sus habituales y clásicas competencias en la materia que examinamos, por un lado, acicateado por los órganos comunitarios, que con harta frecuencia han requerido a sus servicios, por su silencio o pasividad en cuestiones que ex post trascendieron a la misma opinión pública y que llegaron a los despachos bruselenses a través de reclamaciones de grupos testimoniales ecologistas o simplemente de denuncias de particulares que se vieron lesionados por actuaciones empresariales efectuadas sin los preceptivos controles oficiales o con permisos injustificados de estas mismas autoridades, así como también por una opinión pública que como la nacional, si bien no con el deseable empuje, sí va teniendo la visión oportuna para ir exigiendo de los estamentos oficiales mayor control y ex ante, mayor participación oficial en la adopción de medidas protectoras, lo cual, a su vez, se refleja en el mayor compromiso de las autoridades que por ley o reglamento tienen competencias en el Medio Ambiente. No es de extrañar, por esto, que el Gobierno, por mediación del Ministerio indicado, respondiese, aunque no con la altura prevista, mediante la creación de esta nueva unidad orgánica en la que se ha puesto la mayor de las esperanzas para lograr sus fines.

Con lo anterior no queremos decir, ni lo diremos, que el Ministerio de Obras Públicas se haya desgajado de comportamientos propios de «los reinos de taifas» en donde primaba la ley del más fuerte por encima de cualquier dependencia y sumisión lógica, como el autor de estas líneas tuvo la oportunidad de comprobarlo, cuando preparando una edición de legislación ambiental a nivel oficial, tuvo que recorrer en varias ocasiones sus pasillos a fin de convencer a algunos de sus directivos, sobre las bondades de tal edición y su nula relación, con una del mismo, que como tantas otras ediciones oficiales, a pesar de su gran volumen, prácticamente ha pasado desaparecida en los medios profesionales y del intelecto interesados en la temática medioambiental en su prisma legislativo $y$ esencialmente, jurídico. En cualquier caso, por tratarse del Departamento ministerial con mayores competencias sobre terrenos con especial incidencia en el Medio Ambiente, sus actuaciones serán siempre seguidas con especial atención por todos los que demuestran algún interés en la temática que nos ocupa, y esto, incluso, si, como es previsible, España sea uno de los países que en el próximo futuro se incorpore a los que cuentan 
en su haber con un Ministerio del Medio Ambiente, al igual que Alemania Federal, Dinamarca, Irlanda, etc.

Nuestra actitud no puede estimarse ni valorarse como excesivamente crítica sobre los niveles oficiales, puesto que una estadística de nuestros dias, elaborada por la Agencia de las Naciones Unidas en Medio Ambiente, como es la más conocida por sus siglas PNUMA, residenciada en Nairobi, en distintos territorios nacionales y entre sus poblaciones, ha permitido obtener entre otras conclusiones, una muy importante, como es la desconfianza que tales poblaciones, de diferentes países, tienen respecto del compromiso, serio, de sus gobernantes con el Medio Ambiente, opinión casi mayoritaria que tiene su base en el corto compromiso de las autoridades con la protección del entorno, como también en el corto éxito de sus medidas legislativas y de todo otro tipo, lo cual a su vez, nos remite a algo que no podemos ni debemos olvidar: los políticos se mueven por las fuerzas de sus electorados, y cuando en estos no "pesa» como muchos quisiéramos la visión ecológica -que no ecologista- de la Naturaleza, poco harán por sus propias fuerzas, los que intentan representarlas.

La centrifugación de las competencias, actuaciones e intervenciones medioambientales en nuestro país, a pesar del pretendido centralismo del Ministerio de Obras Públicas, llegua casi a la disfuncionalidad más absoluta, con el agravante de llegar a chocar algunas de las medidas adoptadas por centros burocráticos diferentes, que podrán ser mayores a medida de que con el transcurso del tiempo, vayan aumentando las competencias de las Comunidades Autónomas como de los mismos Ayuntamientos (22).

Durante 1989 ha tenido una actuación destacada, lo que evidentemente avala nuestras esperanzas en el papel conductor, mientras dure la situación actual de dispersión de competencias a nivel estatal, en el rol lideral del Ministerio de Obras Públicas y Urbanismo, pues aparte de su ascendente superior jerárquico sobre la Secretaría General de Medio Ambiente, sigue dictando medidas que son, en la mayoría de los supuestos, de gran interés para el Medio ambiente (como es entre otras, la Orden del mismo de 19

\footnotetext{
(22) La Constitución Española sólo otorga al Estado en medio ambiente, la capacidad para aprobar la legislación básica (artículo 149, 23.23: «legislación básica sobre protección del medio ambiente...)). lo cual, para nosotros, es el origen de la situación actual en la materia: por un lado, el Estado no acaba por decidirse sobre el modelo de «ley básica», y las Comunidades Autónomas no pueden ejercitar sus competencias (mismo artículo, sensu contrario, y artículo 148.9) en una actuación muy parecida a la famosa del perro del hortelano, que ni lo hace ni lo deja hacer. Resulta extraño cuando en todos los restantes campos, con mayor o menor fortuna, se ha desarrollado la Constitución, en éste nos encontramos celebrando el $X$ Aniversario de la Constitución, en el mismo umbral que entonces, sin saber cuáles van a ser las competencias que continuará reservándose el Estado y sobre cuáles ejercerán las suyas propias, las Comunidades Autónomas.
} 
de diciembre de 1989, dictando normas para la fijación en ciertos casos, de los valores intermedios y reducidos del coeficiente $\mathrm{K}$. que determina la carga contaminante del canon de vertido de aguas residuales) (Boletín Oficial del Estado de 23 de diciembre) (23).

Sin embargo y a pesar de estas actuaciones, estimamos, aún atrevidamente, que mientras no haya una decidida opción por un modelo netamente Ministerial, más que a cualquier otro, la eficacia de las Medidas medioambientales no será la adecuada ni tendrá el alcance necesario que con ellas se persigue -a no ser que por la misma Presidencia del Gobierno se asuman con todos sus riesgos, los compromisos inherentes al reto que cualquiera de ellas representa ante la sociedad civil de nuestros días- asunción que parece responder a la onda en que nos encontramos, en donde todo el Gobierno, como institución, se hace eco crecientemente de la gravedad de una situación que exige la coordinación de todos, así como la cesión, incluso tácita y sin respaldos legales ni de ningún otro tipo, para conseguir esa deseada unidad de acción, que es la raíz de la misma eficacia, que tanto postulamos. El paralelismo que venimos estableciendo entre España y Europa se refuerza si mencionamos aquellos casos en donde la compatibilidad de actuaciones entre ambas unidades soberanas viene a ser casi total, como son los proyectos de investigación cobijados bajo la protección comunitaria, pero con participación de todos sus miembros, y entre ellos, España (24).

\section{LAS ESTRATEGIAS TECNOLOGICAS DE LOS 90 Y EL COMPOR- TAMIENTO COMUNITARIO EN MATERIA DE MEDIO AMBIENTE}

Creemos que el compromiso encerrado en estas nuevas tecnologías, que como tales son estudiadas, realza aún más la importancia y trascendencia que tendrá en esta década y en sus sucesivas, la problemática medioambiental. El denominado proyecto European Research Coordinating Agency lo Agencia para la Coordinación de

(23) En el campo autonómicó se adoptan también importantes decisiones, como la creación por ejemplo en la Comunidad Autónoma de Madrid, de la llamada Agencia de Medio Ambiente, tan repetida últimamente, que coloca a Madrid a igual nivel que la misma Comunidad Europea

(24) Es el proyecto Eureka, que con una gran amplitud de objetivos y de investigación ha venido a concentrarse, por la mera evolución científica, mayoritariamente, en temas relativos al medio ambiente, de tal forma que para 1990, de 91 proyectos formalmente incluidos en sus parámetros, 67 proyectos se refieren a temas de medio ambiente, de los que, nueve corresponden, al parecer, a España. Que la actividad investigativa europea, y como efecto, la de sus Estados Miembros, gracias a este proyecto, se dirija al Medio Ambiente, contribuye a que todos tengamos más confianza en las posibles alternativas que en el plano decisorio se adopten en los próximos años, por las mismas autoridades europeas, y por derivación, las propiamente nacionales. Esperemos que asi suceda. 
la Investigación Europea, o más abreviadamente conocido como proyecto EUREKA) ha sido definido, entre otros, por García García, que lo sintetiza asi: «enfocar las investigaciones en una serie de proyectos que conduzcan a productos avanzados concretos» (25).

Con semejante proyecto se han puesto en marcha prácticos y reales métodos de asociación entre socios -permitásenos la redundancia- con distintos grados de evolución científica $y$, por tanto, con distintos niveles de conocimientos que por la materia que nos toca, son bastantes pronunciados, lo que a su vez, contribuirá a la difusión como a la puesta al día de los más retrasados, corrigiendo de este modo, indirecto, al no proceder de medidas de tipo tradicional, de sesgo jurídico o administrativo, en todo caso, pero más profundas y eficaces que estas últimas, ya que con aquéllas se colabora a que equipos de personal de distinta procedencia nacional, por su misma relación y juego de interrelaciones, se pongan y vayan poniéndose al mismo nivel, con posible repercusión en sus respectivos ámbitos nacionales e influjo en las correlativas esferas de poder. Por todos estos motivos es por lo que hemos considerado oportuno su misma relevancia titular, dentro de un discurso que como el nuestro tiene un claro matiz jurídico y de pronunciamiento afín a las ciencias del Derecho, sobre todo, por el gran papel que están llamadas a tener en el análisis que realizamos, mucho más cuando cuenten con el auxilio poderoso de estas otras ciencias, más objetivas y neutrales, más asépticas y menos axiológicas o valorativas, que ellas mismas, como son todo este conjunto de ciencias apadrinadoras de estas altas y novísimas tecnologías que ponen al día, más que ninguna otra, las referencias ecológicas.

Ante estos proyectos que se insertan en el cuadro de realizaciones encaminadas a una mejora de los condicionamientos científicos de cualquier actuación, pero mayormente de aquellas que como las del medio ambiente, exigen la concurrencia de una pluralidad de

(25) Ver, Nicolás GARCIA GARCiA: "Nuevas estrategias tecnológicas», El País, 30-5-90, del que son las siguientes frases, que suscribimos totalmente: «... las estrategias productivas que se vislumbran todavía no son definitivas debido a que las tecnologías existentes no son ecológicas. Los paises que tengan la visión de acomodarse a una tecnología ecológica tendrán el futuro en sus manos. Creo que España está bien colocada para abordar las soluciones ecológicas, pero hace falta una clara voluntad política y de reconversión en la forma de pensar de nuestras empresas», cita larga pero sumamente apropiada para subrayar una vez más todo el predicado de una tesis que yace en el centro de una visión que consiste en injertar lo nuevo - como sinónimo de lo ambiental- en el marco de actuaciones de todo tipo con incidencia sobre el entorno, y en especial, que aquellas políticas que van a dicho entorno, directa e inmediatamente. En el fondo, también, todo lo contrario de lo que hasta ahora, con carácter general se viene haciendo en nuestro país: desconocer los costes ambientales de las políticas empresariales en marcha, como si lo ambiental fuera algo totalmente ajeno, ficticio, sin consistencia y sin engarce, pues, en el realismo de las previsiones empresariales y hasta de la misma Administración. 
ellos, que tengan referencias físicas, puesto que a la postre, será sobre la "fisis» -en sentido etimológico y en sentido actual- sobre la que en última instancia actuarán la mayoría de las políticas que les sirven de amparo y protección.

Estimamos que el futuro de cualquier política medioambiental está esencialmente en estos y parecidos proyectos que tienden a mirar más allá de la inmediatez de los problemas más urgentes, como de sus remedios más perentorios, que nos permitan ver, tal como se está haciendo incluso con las famosas campañas mundiales cada día más y más insistentes, lo que puede ser de nuestro planeta Tierra. Lo que acontece, que debido al elevado costo de tales proyectos -sean los de EURERA, sean los cualquiera de los que tienen en marcha principalmente las grandes potencias- sólo las naciones más avanzadas o las colectividades que las mismas integran $-y$ en este terreno Europa ya constituye una potencia mundial-, pueden permitirse el lujo de consagrar importantes recursos de sus economías al esbozo de proyectos que puedan ir dándonos alguna salida sobre un mundo que si bien único, también es cierto que se nos aparece como "cerrado», lo cual, como los grandes científicos saben, no es verdad, ya que nuestro mundo forma parte de uno mucho mayor como es el conocido como Universo (cinco millones de años luz hay entre nuestro Planeta y el último de la galaxia solar en que estamos insertos, ocupa el último lugar fronterizo con otros universos; cinco años son precisos para recorrer tan tremendas distancias). Lo maravilloso de todos esos proyectos es que mientras nosotros estamos con los ojos demasiado fijos en lo que sucede a nuestro alrededor -normalmente el más próximo-, ellos están ya comenzando a dibujarnos, para todos los que tengan interés por conocerlos, las futuras y previsibles salidas que podemos tener cuando nuestra amada Tierra esté cercana al agotamiento de todas sus posibilidades, lo que parece puede ocurrir no muy tarde, cuando estemos rondando, como se vaticina con toda precisión, los primeros años treinta del próximo milenio.

Cuando determinados países, tan apegados por tradición e ignorancia, a las realidades más cercanas, como podría ser el nuestro, otros, como pueden los mismos Estados Unidos, están laborando en la construcción de salidad, perfectamente aceptables, hacia otros planetas en donde la construcción de la vida se reemprenderá con el mismo tesón que hace miles de millones de años se hizo en el planeta que hoy habitamos (fueron necesarios, según los expertos, cuatrocientos millones de años, para que el hombre, al igual que los peces fuera del agua, diera los primeros brincos de adaptación al nuevo -para él-, medio ambiente, y se 
necesitaron otros diez millones de años, para que bajando de los árboles como viera DARWIN se acostumbrase a caminar "recto»), $y$ este nacimiento que los modernos astrónomos llaman «el primer nacimiento cósmico» (que el famoso científico CaRL SAGAN identifica con un "simple nacimiento embrionario", al estar el hombre todavía en su primera etapa de desarrollo, ya que sólo pasará a ser adulto, o sea, a superar su estado embrionario, cuando ocurra su auténtico "nacimiento cósmico», o sea, cuando traspase la barrera del planeta Tierra, para ir hacia otros mundos, como al parecer puede ser Marte, del que nos separan un millón de años luz, y hacia el cual se empleará un año para su desplazamiento $y$ otro año, para el retorno) (26).

Todas esas decenas de proyectos que el programa EUREKA permite ir alumbrando cada año, que configuran ya algún centenar en lo que tiene de existencia, volcados, cada año más en cuestiones medioambientales, son la mejor garantía de que en éste como en otros campos, al grado de desarrollo de algunas comunidades se demuestra por sus más altos standar de información y conocimientos que a su vez autorizan la asunción de riesgos que con posterioridad se ven plenamente justificados al redundar todo el quehacer resultante de los mismos, en la implementación de unas medidas que repercutirán favorablemente en la protección de ese entorno que nos sirve de casa y de refugio.

Con proyectos de investigación como los de EUREKA, la Comunidad Europea se adelanta tanto a los problemas como a su solución, con una previsión anclada en la estimación temporal como una variable de todo punto conveniente para apreciar cuáles van a ser las innovaciones que en todos los terrenos, y especialmente en los tecnológicos, se producirán (los expertos norteameri-

(26) Es tan espectacular lo que se está llevando a cabo en algunos laboratorios norteamericanos, que su simple mención supera la mayor y más utópica de las entelequias. En ellos ya se está partiendo de una sólida premisa: Marte aparece como un planeta perfectamente habitable, que estos científicos llaman ubiosfera 2"-siendo la l, la Tierra-, o también el «ecosistema 2». La vida se creará artificialmente, normalmente bajo protección total, pero que permitirá engendrar alli tanto plantas como la misma agua, pues Marte viene a ser como era el planeta Tierra, hace 400 millones de años, o sea, nuestro planeta, como se prevé llegará a ser en su proceso interminable de desertización-de ahí el temor que subyace en las previsiones de los futurólogos, tamizadas, hasta la saciedad, para evitar cualquier espasmo de terror, entre los que hoy habitamos la Tierra- ¿qué hariamos si se nos dijese que al ritmo actual la Tierra puede convertirse en un desierto como el famoso "Valle de la Muerte»? $Y$ entonces piensan, que nuestra experiencia, ante estas semejanzas planterias, nos permiten disponer de los conocimientos oportunos para conseguir esa «repoblación de Marte», que comenzarían por pequeñas colonias -de «martenautas"- que lentamente irian creciendo hasta formar agrupaciones urbanas. Para ello, se estan haciendo experimentos en Arizona, reproduciendo en algunas granjas las mismas condiciones imperantes en Marte, sobre ocho hombres, que permanecerán totalmente aislados, hasta 1991. Y Marte es uno de entre tantos otros planetas de nuestro conocido Universo que aseguran están esperando al hombre, pues tras él, otros Universos, con centros similares, esperan poder ofrecernos salidas en algo tan esencial como es el espacio. como la más hermosa salida que podiamos imaginar. 
canos que llevan ya años trabajando en los equipos de la NASA para la búsqueda de probabilidades de vida en otros planetas, y por consiguiente, como un aliviadero de la carga demográfica que viene experimentando la Tierra, calculan que si se quiere tener medidas prometedoras para la década de los treinta del próximo siglo, es preciso empezar desde ahora a realizar los trabajos necesarios para ello, en una planeación que como se ve a largo plazo que en cuestiones como la que nos ocupa, son plazos temporales relativamente breves en medio de una existencia que se cuenta por siglos). El ejemplo que nos dan, y que ofrecen a países como el nuestro, en donde la investigación, a pesar de los planes oficiales, aún no ha superado la edad de la juventud, es de gran importancia, y por tal motivo, hemos intentado resumirlo (27).

Cuando la misma comunidad internacional va crecientemente perfeccionando compromisos pasados, agregando nuevos protocolos a pasados tratados o pactos internacionales, encaminados a reducir, si no, a eliminar algunas de las más graves causas contaminantes -como puede ser la contaminación marina producida por causas terrestres-, como es el convenio internacional para la prevención de esta contaminación (actualizado recientemente, en 1986 , en París, momento a partir del cual se declara «abierto» a nuevas incorporaciones de adhesiones, con particular referencia a la Comunidad Europea, y que se publicó en el Boletín Oficial del Estado del 21 de enero y 11 de febrero de 1981, así como la «actualización» de París, en el Boletín Oficial del Estado del 8 de mayo de 1990), parece lógico y natural postular tanto de España, como de la propia Comunidad Europea, mayores y más importantes decisiones en el campo protector de la naturaleza y todas sus manifestaciones - directas e indirectas- a fin de ir poniendo al día todos sus instrumentos para el próximo milenio, del que 1993 constituye sólo un pequeño avance, trascendental dentro de la rueda vital en que se desenvuelve la rutina comunitaria y la existencia de países como España, hasta ahora sin claridad de ideas en los retos que se le presentan por su mismo entorno.

(27) No pequemos de fatuos, si nos regodeamos en el comentario descriptivo de los extraordinarios proyectos que sobre el futuro de nuestro Universo se cuecen en algunos de los más secretos laboratorios de los «gigantes» cuyos logros continúan permaneciendo en el mayor de los secretos, puesto que como diríamos parafraseando a la Biblia, el momento no ha llegado (algún famoso experto como el padre científico de otro gran científico, el físico WEERNER VON BRAUN considera que el público no está habituado a esos grandes viajes de verdaderos exploradores que deberán hacer para alcanzar los límites fronterizosdel planeta Marte, puesto que por allá, también se piensa en la financiación de todos los ingentes gastos, puesta la mira en la misma rentabilidad de todos esos proyectos que siguen debatiéndose con el fin de probar su misma practicidad o utilidad para la gente), pero cualquiera que lea párrafos como los aquí expuestos podrá sentir que mientras se anuncian agotados unos recursos humanos, otros emergen en el horizonte con igual o mayor fuerza. 
En España, de acuerdo con estos parámetros, como venimos repitiendo, no hay afición y no únicamente, como pretende GARCiA GARCIA por falta de competencia tecnológica o científica (28), a pesar de que la temática ambiental va siendo acogida en cuanta manifestación pública, sindical o de partido, tiene lugar entre nosotros (29). Para lo que si la hay es para realizar reformas orgánicas parciales, a manera de parches, que al final conducen a la frustración total (desde el instante temporal de creación de la nueva y flamante Secretaría General de Medio Ambiente, y prácticamente a lo largo del primer semestre de 1990, cuando redactamos este trabajo, toda su coheteria se ha concentrado en la provisión de su organigrama, resultando que en este mismo período, su presencia en las páginas del Boletín Oficial del Estado se ha visto centrada en algo tan trascendente para el medio ambiente, como son los nombramientos de los nuevos titulares de los nuevos puestos orgánicos con competencia en la materia que examinamos; a lo largo de tal semestre, y en especial, durante el mes de mayo se han ido sucediendo los distintos nombramientos de Subdirectores generales, asignados a las Direcciones Generales de Política Ambiental o a la de Coordinación Ambiental, contribuyendo a que la celebración del Día Mundial del Medio Ambiente, que como todo el mundo sabe tiene lugar el 5 de junio, haya coincidido con una de sus celebraciones más tristes y anodinas, coincidiendo tambien con unas declaraciones periodísticas del titular de la Secretaría General, en las que uno no sabe admirar más si la rutinariedad de la entrevista o su escasa relevancia, al ir desplazada a la parte interior de los medios de comunicación social, justamente en un momento en que en otros países ribereños con el Mediterráneo, como es Italia, se sometía a referéndum nacional y popular nada menos que el tema de la prohibición de la caza, lo cual prueba hasta el límite de lo probable que nos movemos por unas pautas tan particulares y con tan poca analogía con las vigentes en los demás paises comunitarios, que en este punto nuestra adhesión a los estándares culturales de Europa no es más que una pura ficción, mientras no se demuestre, con hechos, y no con simples palabras, lo contrario). Nuestro juicio aún teñido de pesimismo, no deja de ser leve ante una realidad cuyo descuido a

(28) En el artículo antes citado: “En mi opinión, por lo que no podemos aprovecharnos lo debido de los programas tecnológicos europeos es por la falta de formación profesional».

(29) Así, dentro del paquete de acuerdos a tomar en la segunda fase de la llamada concertación social entre Sindicatos y Gobierno, en el verano de 1990, figura el tema de «salud laboral y medio ambiente", y en unas jornadas celebradas por las mismas fechas por el Partido Popular, también la temática de medio ambiente figuraba entre los objetos de estudio. Estámos alcanzando el momento álgido de la moda de un tema, que entre nosotros, se caracteriza por el empleo excesivo de palabras -a la postre, de retórica- por encima de planes concretos de estudio e investigación sobre aspectos puntuales.

REVISTA DE ESTUDIOS. -8 
nivel interpersonal no deja de ser lacerante, cuando tanto se han desarrollado nuestras condiciones de vida, pero una vez más sentimos auténtico placer, como ya denostó VALLE INCLÁN en ser esperpénticos. Extraña bufonada en un mundo que cada vez más se rige por unas coordenadas de racionalidad y mesura que por aquí resultan chocantes, cuando no siempre burladas.

Ahora bien, España es uno de los países que más convenios internacionales habrá suscrito, ratificado y puesto la firma, siendo así que para cualquier observador extranjero que a través del Diario Oficial del Estado español, quisiese obtener una primera impresión de en qué órganos están centradas las mayores competencias en medio ambiente, se inclinaría ante el Ministerio de Asuntos Exteriores, encargado de suscribir y poner la firma a los numerosos convenios, protocolos modificativos, adhesiones posteriores, actualizaciones, etc. (30). El que se cumplan o no, merced a la debilidad de los propios instrumentos internacionales, es otro cantar, como diríamos con el poeta, pero nuestro país no pasa de la buena impresión que tal actitud representa ante la Comunidad Internacional (lo que no nos libera de las críticas de esta última, como ha sido buena prueba la ya comentada conferencia de BERGEN en Noruega).

Como conclusión de todo este largo exordio, hecho con la cordialidad evangélica, como diría un conocedor de los textos bíblicos, en los que tanto debemos beber como signo de respeto a una naturaleza cuya creación es divina, es bastante desequilibrado y peyorativo para un país que como el nuestro sigue sin darse cuenta en relación con el medio ambiente, con lo que tenemos y lo que debemos hacer para conservarlo (lo primero al reconocer como hacen la mayoría de los estudiosos de que nuestro país es la región europea que cuenta con mayor variedad de paisajes y ecosistemas, y lo segundo que para evitar que dicha riqueza desaparezca o experimente lesiones de tal gravedad que presuman su potencial destrucción exige que todo el país se comprometa en una cruzada de signo proambientalista cuyas últimas raíces descansen en la

(30) Asi, durante el mes de mayo de 1990, reseñamos los siguientes: Denuncia por España del Reglamento núm. 15 sobre prescripciones relativas a la homologación de vehículos equipados con motor de encendido por compresión en lo que se refiere a la emisión de gases contaminantes por el motor, anejo al Acuerdo de Ginebra de 20 de marzo de 1958, sobre el cumplimiento de condiciones uniformes de homologación y reconocimiento recíprocos de la homologación de equipos y piezas de vehículos de motor (publicado en el Boletín Oficial del Estado de 29 de julio de 1970, 3 de junio de 1982 y 27 de agosto de 1986). Esta última denuncia se hace por el Ministerio de Asuntos Exteriores español el 20 de abril de 1990 (y se publica en el Boletín Oficial del Estado de 4 de mayo) surtiendo efectos desde el 15 de febrero de 1991. Otra medida de este Ministerio es la inclusión de nuevos «humedales» en el Convenio Internacional de los mismos, para favorecer la creación de "habitats» de aves acuáticas, hecho en Ramsar el 2 de febrero de 1971 (esta ampliación de humedales por España ocupa varias páginas en el Boletín Oficial del Estado de 8 de mayo de 1990). 
correcta y ortodoxa información, proporcionada por nuestras propias aulas y por el estudio de esos mayores estándares culturales de los países a los que nos hemos unido con nuestra incorporación al Mercado Común. Pedir también, y muy principalmente a nuestros legisladores, que adopten medidas oportunas y con tendencia a la perennidad, ancladas en el Derecho Comparado, tanto como en el autóctono, y sobre todo, que se apruebe definitivamente esa legislación básica que permita su desarrollo tanto desde el Estado central, como del de las Autonomías, y por derivación, a los Ayuntamientos llamados todos y cada uno de estos niveles territoriales, a desempeñar un papel sucesivo pero fundamental en la lucha contra las plagas que asolan nuestro suelo y exterminan nuestra flora y nuestra fauna).

\section{BREVE REFERENCIA A LAS CORPORACIONES LOCALES EN LA LUCHA MEDIOAMBIENTAL}

Los Ayuntamientos, tanto a nivel nacional como europeo, pueden hacer mucho y contribuir de manera decisiva al éxito en esa que hemos denominado "cruzada ambientalista», al ser estas Corporaciones las más próximas y conectadas con las realidades que todos sus ciudadanos viven diariamente $-y$ sufren con la misma intensidad-. Normalmente, sus actuaciones tienen mayor incidencia que las de ámbito más global y general, aunque sólo sea por su relación inmediata con un determinado territorio en el que pueden reflejarse mejor que en ninguna otra parte, tanto los éxitos como los fracasos, que cualquiera podrá ver y comprobar (31).

Razones en contra de esta intervención municipal, para que no sea puramente simbólica o testimonial, no faltan, dada la tradicional penuria que de medios económicos vienen padeciendo las Corporaciones Locales de algunos países europeos (penuria clásica entre nosotros, y con menos ámbito en otros latinos), pero nos encontramos en un momento histórico de gran interés, puesto que, a nivel

(31) Estas campañas normalmente suelen reproducirse a nivel intermunicipal, de modo que las posibles iniciativas adoptadas por algún municipio en particular, son ex post, copiadas por otros, lo que ocurre en aquellos que por su tamaño o su misma condición lideral en el terreno corporativo local -las grandes ciudades- ejercen un enorme atractivo, sobre municipios de similares características (la supresión de la famosa niebla en Londres, ha dado lugar a múltiples imitaciones por otras ciudades que después de aquélla, han venido a sufrir nieblas más gravosas como son las ocasionadas por los escapes de los automóviles u "otros vertidos»). Cada municipio tiende a imitar aquellas iniciativas implantadas en otros de simil tamaño, pero en cualquier caso, abogamos por la eficacia de estas campañas -que pueden ser de limpieza urbana- "Mantenga limpia la ciudad" o como la de aquel municipio colombiano que lanzó un spot televisivo sumamente efizaz y agresivo, que decía "Si usted no colabora a limpiarla, por lo menos no ayude a ensuciarla» (en Bogotá, durante todo un año, 1989), o de la "Plante usted un árbol». etcétera. 
europeo, se cuida con mimo para que estas Entidades públicas cuenten con los medios financieros propios para hacer frente a los compromisos cada año crecientes que les plantean los mismos núcleos sociales que en ellas conviven (autonomía cada lustro mayor, puesto que el mismo Estado, hasta ahora visto más como "protector» que como "árbitro», se ha dado cuenta de la escasa, por no indicar nula, conveniencia que tiene el compaginar sus actuaciones con las demandas incesantes de Municipios escasos de recursos, por lo que se viene aprestando, durante los últimos años, en el paulatino $y$ progresivo reconocimiento de fuentes propias de ingresos para estas Entidades en las que muchos autores, desde CALVo SOTELO hasta SALEILlES vieron los orígenes de la verdadera convivencia social, y del Estado).

Ya hemos venido detectando en las páginas anteriores algo de esta mayor relevancia participativa y decisoria que en el campo medioambiental están teniendo nuestras Comunidades Autónomas que, no obstante la carencia de una ley general básica de titularidad estatal, no están dejando de ocuparse puntualmente de intervenciones en nuestro campo (la Agencia del Medio Ambiente de la Autonomía madrileña está teniendo una cadena de actuaciones destacadas para la mayor concienciación de colectivo tan numeroso como es el capitalismo, con campañas perfectamente estudiadas y dirigidas a un público que en el fondo necesita y quiere ser estimulado a un más correcto comportamiento con esa naturaleza que apenas divisa desde su estrecha calle y no menos pequeño habitáculo (32), quedando mucho por hacer, como cualquiera puede comprobar si repasa los temas y los puntos en los que dicha participación pudiera fructificar con éxito para todos (33).

Cuando entrevemos las enormes posibilidades que tiene cualquier campaña lanzada desde el medio urbano y para él, para alguna de las finalidades medioambientales más destacadas, como puedan ser la misma limpieza de la ciudad (esos eslóganes que esporádica-

(32) Por Decreto 37/1989, de 16 de abril, se aprueba por la Consejeria de Presidencia del Gobierno autonómico madrileño la estructura de esta Agencia, que desde su primer momento ha tenido un papel sumamente activo, tal como se refleja en los mismos medios de comunicación social. Para una mejor comprensión de las competencias en la materia, conviene analizar las competencias en materia de ordenación del territorio y urbanismo, para lo que puede consultarse entre otros, el Decreto 51/1989, de 6 de abril, de la Consejeria de Politica Territorial (el primero se publica en el Boletín Oficial de la Comunidad de Madrid, en adelante BOCM, del 20 de abril, y el segundo, en el del 24).

(33) Nos referimos por ejemplo a la colaboración ciudadana en algo tan importante como es para Madrid y las demás ciudades, de la llamada "selectividad de las basuras», mediante la separación de sus clases: papel, periódicos, vidrios, productos que pueden ser reciclados y por tanto no despilfarrados (como se hace en algunas ciudades europeas -véase. Alemania Federal, Tribuna Alemana núm. 1.010, 23 de mayo de 1990, "Seleccionadora de botellas"-, y que comienza a plantearse en la capital de España, donde se han celebrado las primeras jornadas sobre este tema, en la primera semana de junio) 
mente vemos rotulando algunas de sus calles, sin que los ciudadanos se fijen en ellos, por considerarse ajenos a su mismo planteamiento, por no haber participado en la elaboración de sus propósitos y ser sólo "campañas» desde las alturas, lo que tan desgraciadamente repercute en el mismo estado físico de nuestras ciudades, a veces tan sucias que apenas su simple visión, imaginando cuán más hermosas estarían si fuesen más limpias) o la concienciación en sus habitantes para mantener determinados comportamientos cívicos que tan buenamente inciden en el «bienestary de los conciudadanos (como pueden ser las campañas sobre el ruido, los tonos de voz, el modo mismo de cerrar las puertas, tan bruscos y fuertes que algunos filósofos con ellos han caracterizado el "grado de malestar» de nuestras poblaciones urbanas, que con sus "portazos» quieren hacer oír su disgusto, su malquerer y su nula solidaridad, puede leerse con delectación, pero también con melancolía, las reflexiones, diríamos, no de un "paseante solitario» al estilo rusoniano, que exponía el profesor COTARELO en uno de los medios de comunicación social más masivos de nuestra sociedad, bajo el título, sumamemte ilustrativo para todo español, como es el de "Donde Cristo dio las tres voces", en donde llega a afirmar esto que cualquier ambientalista suscribiría: «El ruido, especialmente el innecesario, es una forma de contaminación del medio ambiente y más repugnante que algunas otras», lo cual, es obvio, es obra y causado por ciudadanos que desconocen lo perjudicial que puede ser su griterío como lo es un mal gesto o insolidario con sus paisanos, lo que acaso sólo podrá enterarse de oportunas campañas en las que él mismo participe para que se dé cuenta de lo que hace falta en este terreno).

Algún autor, como ROBERT A. DAHL se pregunta si nos encontramos en una nueva $y$ definitiva etapa del proceso democratizador de la humanidad, que consistiría en su profundización total, una verdadera y auténtica transformación democrática, «... que abarcaría un incremento significativo de la participación de la vida ciudadana en la vida económica y política...», y nosotros, siguiendo su hilo de razonamiento, añadiríamos que si ello es cierto, donde más se notaría semejante proceso sería en la vida urbana y local, en donde más cabe imaginar, más que en ninguna otra instancia política ni nivel territorial, una mayor participación de todos aquellos que estén simplemente interesados en hacerlo, pues la inmediatez de la vida local, tan cercana en todas sus manifestaciones a los propios intereses de sus miembros, hace que sea en las ciudades donde tengan entrada las posibles mayores innovaciones de fórmulas participativas (34).

(34) ROBERT A. DAHL: Democracy and its critics. Yale University Press, 1989, 397 págs. Puede leerse una interesante reseña de este libro en la revista Facetas, 3, 1990, pp. 74 y ss. 
Entendemos, además, que pocos terrenos existen en toda la actividad administrativa en que más viable y necesaria es esa participación ciudadana que en el medio ambiente, en donde todas las colaboraciones, por mínimas que sean, son más máximas valorativamente en el terreno de los hechos $y$, por supuesto, en el de resultados, puesto que la defectuosa actuación o el incívico comportamiento de un ciudadano o un grupo de ellos repercutirá para mal en la calidad de vida general (considérese, aunque sea extremo, el caso tan reiterado y frecuente en nuestro país de los autores de los incendios provocados que asolan todos los veranos algunas de las Autonomías con mayores recursos forestales; basta que sea uno para que el daño que puede producir con acciones de tal tipo pueda ser inmenso, más que proporcional a su pura individualidad. El ejemplo puede multiplicarse hasta el agotamiento como cualquiera puede comprobar en su misma ciudad, cuando recorre cualquiera de sus rincones, parques, calles o parajes artísticos, pudiendo afirmarse que de nada valen los esfuerzos de los ediles municipales si sus gestiones no se ven ratificadas $y$ refrendadas diariamente por la mayoría de los ciudadanos, y pensamos que en el futuro se aumentarán los llamamientos a esa ciudadanía para conseguir su mayor participación en todas las decisiones municipales, como ya lo estamos viendo en España, sobre todo en las grandes ciudades).

Creemos que si bien algunos de nuestros grandes Municipios, como el de Madrid, están teniendo iniciativas destacadas en la protección de sus contaminados espacios urbanos (35), continúan careciendo de la adecuada perspectiva global y de coordinación con los restantes núcleos municipales, tanto a escala nacional como propiamente comunitaria o europea, comportándose como si

\footnotetext{
Los propios partidos políticos, por ejemplo en España, recurren cada día más, en el ámbito local, a requerir la opinión directa de los ciudadanos en aquellas cuestiones que como el tráfico más sufren diariamente en todas sus actividades - fue hace poco en Madrid, con el referéndum sobre prohibición posible del tráfico de coches privados en determinados días, o aquella otra de no utilizar el vehículo particular algún día a la semana, etc.-. Ver también revista Departements et Communes núm. 50, marzo 1989, pp. 67 y ss.: "L'information et le participation des citoyens". Con un carácter más genérico, Federación Española de Municipios y provincias: las corporaciones locales y la comunicación ciudadana, 1989.

(35) Aun en el caso de Madrid, que cuenta a su favor con numerosas y cada día más persistentes medidas protectoras del medio ambiente, no dejan de presentar un alto grado de espontaneidad, que en términos competenciales, sería sinónimo de ingenuidad, sin que se vea respondan a una visión de cierta perspectiva y en coordinación, como indicamos más adelante, con otros núcleos urbanos del territorio español, con los que puede mantener determinadas pautas de interés, y por consiguiente, de actuación común. A su vez, algunas de las iniciativas que en él se han pretendido instaurar, han tomado modelos en ejemplos extranjeros (como de todos es sabido fue la causa inmediata de la inspiración de la iniciativa de Izquierda Unida, de limitar el tránsito privado de coches, tomada de la ciudad italiana de Milán), todo lo cual nos lleva a lamentar la escasa imaginación que en este terreno se detecta, aunque anotemos algún cambio sobre este punto, que esperamos ver consolidado cada vez más, como arriba referimos.
} 
fueran islotes aislados - valga, mejor que nunca, la redundancia- en el panorama de la lucha contra todos los tipos de contaminaciones que nos invaden y asedian a los que en ellos residen y trabajan. Muy tímidamente, la misma Federación Española -nacional- de Municipios está comenzando a ocupar un lugar en este debate, marginando en sus planteamientos, aunque sea muy reducidamente, sus habituales $y$ tradicionales posiciones de defensa a ultranza de las competencias municipales, como si éstas no se vieran disminuidas, por no decir eliminadas, ante unos comportamientos que, como los que lesionan el aire de nuestras ciudades, remontan su origen bastante más de los puros límites territoriales de nuestras Corporaciones Locales, lo cual, seguir obstinándose en no verlo no puede conducir más que a un empeoramiento, acaso irremediable, de la atmósfera todavía no totalmente malsana con que contamos.

En la capital del Estado español podemos indicar, como medidas estimulantes contra la contaminación, la del acuerdo celebrado entre el Ayuntamiento y la Compañía "Gas Madrid, Sociedad Anónima», para fomentar el uso de gas natural en los servicios de calor doméstico, como se subraya en su mismo Protocolo de Acuerdo (publicado en el "Boletín del Ayuntamiento» número 4.858, de 18 de marzo de 1990): "Dentro de los problemas de la contaminación de Madrid, sigue ocupando un lugar importante la contaminación por dióxido de azufre, que procede fundamentalmente de los procesos de combustión de los generadores de calor domésticos, siendo tanto más importante su emisión cuanto mayor sea el contenido de azufre por termia en los combustibles. En 1982, cuando se inició el Plan de Saneamiento Atmosférico, ya se preveía la sustitución de los combustibles sólidos en los generadores de calor domésticos por otros más limpios o menos contaminantes, entre los que ocupa un lugar destacado el gas natural o el manufacturado...» $Y$ añade, en una clara relación de toda esta política de saneamiento atmosférico del Municipio madrileño, a la obligación, mayor que nunca, que tiene en su incentivación la existencia de una política que, como la comunitaria, está llamada a tener un papel más influyente en éste: «... el criterio de calidad del aire que ya estableció el Ayuntamiento de Madrid viene hoy impuesto por las limitaciones establecidas con motivo de la entrada en vigor del Real Decreto 1613/1985, que aplica la Directiva 80/779/CEE...», terminando por confesar, no obstante, que "sigue siendo una realidad que en diversas estaciones de la Red de Control se superan los niveles fijados por la citada Directiva..." (36),

(36) Aunque situados en puntos estratégicos de la ciudad de Madrid, estos puestos de la red de control del grado de contaminación de la atmósfera capitalina, se han sometido 
razones todas las expuestas que justifican el plan de ayudas que se establecen a fin de conseguir esas sustituciones de calefacción entre los habitantes del hábitat madrileño.

Las iniciativas de los demás partidos con representación en el Ayuntamiento, también se han multiplicado en los últimos años, de algunas de las cuales podemos tener noticia a través de las reseñas - resúmenes que de sus Plenos nos trasladan las páginas del «Boletín Oficial del Ayuntamiento», como la del PSOE en orden a una reunión de una Comisión informativa mixta entre las Areas de Medio Ambiente y Transportes, para dilucidar las medidas de tráfico restrictivas que sean previsibles ante supuestos determinados de fuerte contaminación atmosférica (Boletín ya citado de 8 de marzo de 1990), o la propuesta de este mismo grupo político en orden a la modificación urgente de la Ordenanza municipal general de Medio Ambiente urbano, para incorporar a la misma lo establecido en la Directiva 85/203/CEE, relativa a las formas de calidad del aire por dióxido de nitrógeno, adoptando los valores límites y guía que figuran en dicha Directiva (en el mismo Boletín) o la propuesta, también del grupo representativo del PSOE (en el Pleno municipal del 24 de noviembre de 1989, resumida en el «Boletín del Ayuntamiento de Madrid» de 15 de marzo), en orden a la instalación de catalizadores en todos los vehículos circulando por el núcleo urbano, en los que técnicamente sea posible, y que todos los vehículos nuevos que se adquieran vayan dotados de tales equipos descontaminantes, lo que traería, como consecuencia, a juicio de esta propuesta, la instalación de surtidores de gasolina sin plomo en los parques municipales, instando a las demás Administraciones a la adopción de medidas similares, procurando, para aumentar la ejemplaridad de esta medida, que los vehículos que incorporasen estos catalizadores fueran provistos de las correspondientes señas de empleo de tales anticontaminantes. Iniciativas, propuestas, sugerencias que nos revelan el mayor interesamiento que demuestran y exhiben todos los grupos políticos representativos, que ven como sus electores quieren hacerlos partícipes de una problemática que a todos nos afecta y que cada día se agrava por doquier.

Medidas similares se adoptarán -si no lo han sido- por las demás ciudades de nuestro ámbito territorial, en que el grado de

últimamente al control de los órganos comunitarios, para comprobar su grado de alineación con establecimientos similares europeos, y para su conformidad con los requisitos que sobre ellos tienen previstos la propia CEE. El Ayuntamiento de Madrid adoptó en su Pleno de 31 de octubre de 1989 un acuerdo instando al Gobierno de la Nación, a los efectos de la lucha contra la contaminación producida por los dióxidos de nitrógeno, «se corrijan los precios de los productos derivados del petróleo de tal forma que nunca la gasolina sin plomo tenga un precio superior a la gasolina súper y que se proceda a la distribución adecuada de surtidores para que los vehiculos con catalizador tengan facilidad de repostarn (Boletín de 8 de marzo de 1990). 
contaminación presenta los niveles de gravedad que hacen aconsejable actuaciones de signo intervencionista como éstas, aunque repetimos que no responde a una visión coordinada de unas necesidades que son comunes, por reiterarse en todas ellas, que es justamente lo que persigue la Comunidad Europea con todas las medidas que adopta, dado que en múltiples ocasiones las ciudades, si bien sufren más inmediatamente que cualquier otro nivel territorial los efectos de la contaminación, en cualquiera de sus vertientes, también es cierto que carecen del horizonte adecuado y correcto para superar los pequeños espacios. Si la Comunidad Europea persigue esa «Europa natural» que muchos identifican con un lejano pasado, aunque con una realidad muy presente y de porvenir, hay que considerar que los Municipios - $y$ en mayor grado aquellos que, por contar con millonaria población, tienen mayores riesgos de caer en las periódicas alertas de peligro para la salud y el bienestar de sus ciudadanos (37).

Es verdad que las grandes batallas se ganan en reducidos espacios, por lo que los territorios de nuestros Municipios son el mejor campo para conseguir triunfos concretos y palpables contra tantos males que atacan nuestro medio ambiente, y muy en particular aquellos que se manifiestan a través de la contaminación que producen el tráfico, las industrias en ellos residenciadas, los vertidos de todo tipo sin depurar que se lanzan al exterior sin control alguno (de residuos industriales, de aguas fecales, etc.); pero también lo es que poco se puede conseguir si en ello sólo quiera verse un problema de ámbito exclusivamente nacional, cuando por muy localizado que esté el daño, siempre superará con creces su hinterland local para incrustarse en una panorámica nacional, que asi debe contemplarse si se quiere contar con una correcta política de prevención 0 , al menos, de reparación de perjuicios causados, aunque este planteamiento no puede servir de excusa para negligencias o deficiencias, sino más bien como un acicate para una más adecuada planificación de actuaciones y medidas que posibiliten en grado creciente la consecución de un entorno más idóneo para todos sus habitantes.

(37) El País Vasco, que debido a una fuerte industrialización desde últimos del pasado siglo, viene padeciendo sus efectos, se ha puesto a la cabeza de las Comunidades Autónomas en la valoración de los males para que el medio ambiente que conlleva, tal como nos lo refleja el número monográfico dedicado al tema "Ordenación del territorio y medio ambiente», que fue el tema concurrencial del II Congreso Mundial Vasco, celebrado en Vitoria en 1987, y cuyas ponencias y trabajos se publican en la revista del Instituto Vasco de Administración Pública, en 1988, y donde se contiene un trabajo del Profesor FERNÁNDEZ RODRÍGUEZ versión actualizada de otro anterior suyo, sobre "vecindades industriales y su impacto en el medio ambiente», en el que subyace la transfronterización de los efectos de esas "vecindades» como tanto nos lo demuestran la lluvia ácida que tantos perjuicios está causando en zonas colindantes con determinados enclaves industriales fuera de su circunscripción territorial. 
REALA-1990, núm. 248. VAZQUEZ DE PRADA, VALENTIN R.. MEDIO AMBIENTE: ANALISIS CO...

REALA-1990, núm. 248. VAZQUEZ DE PRADA, VALENTIN R.. MEDIO AMBIENTE: ANALISIS CO... 
REALA-1990, núm. 248. VAZQUEZ DE PRADA, VALENTIN R.. MEDIO AMBIENTE: ANALISIS CO...

\section{CRONICAS}


REALA-1990, núm. 248. VAZQUEZ DE PRADA, VALENTIN R.. MEDIO AMBIENTE: ANALISIS CO...

REALA-1990, núm. 248. VAZQUEZ DE PRADA, VALENTIN R.. MEDIO AMBIENTE: ANALISIS CO... 